\title{
Insuring Educational Risk: Opportunities versus Income
}

\author{
DIRK SCHINDLER \\ BENJAMIN WEIGERT
}




\title{
Insuring Educational Risk: Opportunities versus Income
}

\begin{abstract}
We develop a model of education where individuals face educational risk. Successfully entering the skilled labor sector depends on individual effort in education and public resources, but educational risk still causes (income) inequality. We show that an optimal public policy consists of deferred skill-specific tuition fees, lump-sum transfers/taxes, and public funding of the educational sector. We argue that improved educational opportunities matter more than direct income transfers in a Second-best setting. Contrary to standard models of income risk, it is not optimal to use a proportional wage tax, because combining skill-specific tuition fees and public education spending provide both insurance and redistribution at lower costs. A wage tax is only optimal if skill-specific tuition fees are not available.
\end{abstract}

JEL Code: H21, I2, J2.

Keywords: human capital investment, endogenous risk, learning effort, optimal taxation, public education.

Dirk Schindler

University of Konstanz

Fach $D 133$

78457 Konstanz

Germany

Dirk.Schindler@uni-konstanz.de
Benjamin Weigert

Justus-Liebig-University of Gießen

Department of Economics

Licher Strasse 66

Germany - 35394 Gießen

benjamin.weigert@wirtschaft.uni-giessen.de

June 24, 2008

We are indebted to Alexander Haupt, Bas Jacobs, Leo Kaas, Tim Lohse, Normann Lorenz, Christian Lumpe, Agnar Sandmo, Guttorm Schjelderup and Stefan Zink as well as participants of seminars and conferences in Gießen, Warwick, Oslo, München, Konstanz, Garmisch-Partenkirchen and Gent for valuable comments. The usual disclaimer applies. An older version of this paper has been called "Educational Risk and Public Policy: Taxation, Fees, Loans, and Incentives.” 


\section{Introduction}

For more than 30 years, rising wage inequality, especially between incomes in the skilled labor sector versus those in the unskilled one, is observed, see, i.e, Krugman (1995) or Katz and Autor (1999). This type of inequality is also accompanied by income risk. The reason is that employment as skilled worker requires both successful graduation in the higher education sector and finding a suitable job later on. Both is by far not guaranteed, see, e.g., OECD (2007, Indicators A3 and A8). Accordingly, (educational) risk of failure to enter the skilled sector is a salient feature of human capital investment and distributional inequality interacts with income risk.

What happens then to those households, who fail and end up as unskilled, and how can welfare of the unskilled workers be increased in an inequality-averse society? Different approaches to this problem can be observed: in welfare policies the main focus is on redistribution via direct income transfers as, e.g., the earned income tax credits in the USA. An additional strategy is to implement minimum wages, which are in place, i.e, in the U.K. and in France. A more recent political agenda is to foster educational opportunities, to decrease drop-out rates (especially at schools) and to ensure that the major part of the population attends higher education. This is part of the so-called renewed 'Lisbon-agenda' in the EU, announced in 2005 as strategy for growth and jobs (EU-Council, 2005).

However, in the political debate, there seems to be no consensus on what the best strategy is and the implementation of the 'Lisbon educational offensive' in the EU member countries is doing poorly according to a EU press release in October 2007 (EU-Commission, 2007). Even more amazing - and to the best of our knowledge - these topics have been entirely neglected in the economic literature, although stylized facts strongly indicate that drop-out rates are non-negligible and that higher education has enormous effects on the labor market perspectives of households (OECD, 2007, Indicator A8). Consequently, the very important, but still pending question is: Should the government redistribute ex ante by increasing educational opportunities or ex post by means of income redistribution?

This paper shows that in a Second-best world, where learning effort cannot be controlled by the government and collecting tax revenue induces distortions, 
it is more important to increase educational opportunities, measured as the success probability to graduate, than to provide ex-post income insurance by direct transfers from the skilled to the unskilled.

Thereto, it is not optimal to use distortionary wage taxation, if the government can apply deferred skill-specific tuition fees. Educational opportunities are enhanced by an improved resource endowment in the educational sector - which simultaneously counteracts tax-induced negative incentive effects in learning effort. The combination of skill-specific tuition fees and public funding of the educational sector simultaneously allows for redistribution and insurance at lower costs compared to wage taxation and direct income transfers.

In short, the main intuition is: Collecting revenue in a Second-best world is costly, but spending the revenue in the educational sector instead of granting income transfers, ceteris paribus, mitigates distortions in learning effort and decreases the marginal costs of taxation, whereas both ways of spending decrease income risks and increase welfare.

The main idea behind the outline of our models rests on (i) that wage inequality interacts with educational risk and (ii) that learning effort (how time is spent at school respectively at university) and resource investment in the educational sector endogenize the risk of failure to enter the skilled sector, opening another channel for governmental policy.

The accelerating wage inequality since the 1980s is driven by globalization and increasing international trade (Krugman, 1995) and - to the most part - by skill-biased technological change (Katz and Autor, 1999). Both are seen as either putting pressure on low-skilled wages and favoring skilled labor (the "American way") or creating unemployment in the low-skilled sector, if there are labor market rigidities (the "European way"). Jacobs (2004) supposes the wage differential to increase even more in the future, due to the growth rate of skilled labor supply lacking behind the demand for skilled workers - implying that wages can be even less forecasted than by now.

As future wages can hardly be predicted, when investing in human capital, ${ }^{1}$

${ }^{1}$ See, e.g., Carneiro et al. (2003) showing for high-school and college graduates that the overwhelming part of variance in returns to education cannot be predicted by students at the time of making their investments. 
wage inequality and educational risk are intertwined. Consequently, educational risk can be twofold (Levhari and Weiss, 1974; Kodde, 1986, 1988): the most obvious is the risk to fail graduation, implying that most of the resources invested might be lost. The other type of risk is the uncertainty about future wages and employment opportunities.

Analytically, the cases of failed graduation and failed (well-payed) employment can be described in the very same way as uncertain future wages, if the probability of failure is exogenous. However, to assume that this probability is exogenous for individuals is not plausible. Therefore it appears reasonable that to some degree the probability to graduate and to get a job as skilled worker is the result of individual choices such as learning effort. Obviously, the effort chosen by individuals will, amongst others, depend on the quality of the educational system and on public resources spent on education.

Endogenizing learning effort then opens another channel, through which governmental intervention both via public spending and tax revenue collection influences market outcome: On the one hand revenue collection can have negative effects on learning efforts, increasing the risk of failure in education and with it income risk. On the other hand, the government gains another insurance device in increasing the success probability and providing ex ante insurance.

In order to analyze these topics, we apply a two-period model, where the individuals first decide on their learning effort. This decision determines their success probability in higher education and in entering the skilled sector. Then risk realizes and the individuals choose their labor supply either as skilled workers or as unskilled ones. The benevolent government can use a proportional wage tax and a combination of tuition fees and skilled-contingent loans in order to finance both a general lump-sum transfer and public funding of the education system. Public educational spending is assumed to increase the success probability, because an enhanced quality in the educational sector, e.g., an increased number of teachers at university, improves the learning technology.

The proceeding is as follows. The next section contains a short overview on related literature. In section 3, we present the model, and examine household behavior in the fourth section. Section 5 then establishes the First-best allocation as benchmark case, whilst section 6 introduces public policy and section 7 
determines the optimal tax and education policy. Section 8 concludes.

\section{Related Literature}

Our paper builds on and extends a large literature on optimal tax policy in case of risky human capital investment and wage uncertainty.

It is well known from the work by Eaton and Rosen (1980a,b) as well as from an extended model by Hamilton (1987) that it is optimal to implement a distorting wage tax, because the insurance provided will outweigh the excess burden, if wage income is subject to (idiosyncratic) risk. A similar result is derived in Kanbur (1980), where households have to decide, whether to work in a risky entrepreneur sector or to earn deterministic wage income as employee. There are no redistributive motives, because labor market equilibrium implies that the expected utilities of all households are equalized, but differentiated taxation provides insurance. The result is extended by Boadway et al. (1991) to an optimal linear income tax scheme.

More recent papers, dealing with risky human capital formation and risky skilled labor income, are, e.g., García-Peñalosa and Wälde (2000), Wigger and von Weizsäcker (2001), and Jacobs and van Wijnbergen (2007). Basically, all these contributions show that a graduate tax, accompanied by some direct education subsidies, is optimal in order to insure individuals against income risks. Anderberg and Andersson (2003) show that education itself can have an insurance effect and should in this case be overprovided, because this also increases tax revenue.

Common to all these papers is that they treat the risk as exogenous. There is no choice on learning effort, and therefore no effect of taxation on the probability distribution itself. ${ }^{2}$

Mostly related to our modeling approach is the work by Andersson and Konrad (2003a,b), who also examine endogenous learning effort in a risky setting. They focus on possible private insurance instead of governmental instruments (Anders-

\footnotetext{
${ }^{2}$ The exception is Wigger and von Weizsäcker (2001), who briefly examine the case of ex-ante moral hazard. However, they restrict to two possible effort levels, and the government cannot influence the learning technology by public educational spending.
} 
son and Konrad, 2003a) as well as on hold-up problems and time-consistent taxation in case of a Leviathan government (Andersson and Konrad, 2003b). However, in contrast to our analysis they do not consider direct public spending in the educational sector and endogenous labor supply in the working period. ${ }^{3}$ Hence, they are not able to deal with the issue of providing ex ante versus ex post insurance against educational and income risk.

\section{The Model}

We consider an overlapping generations economy in which individuals of each generation live for two periods of time and die at the end of the second period. In the second period each individual gives birth to one child so that the population remains constant over time; each cohort is normalized to one adding up to a total population of two. In each period individuals are endowed with one divisible unit of time. At the beginning of the first period individuals invest into higher education and start working in the second period. ${ }^{4}$ Following Glomm and Ravikumar (1992), we assume that both education in the first period and working in the second period are time consuming activities which generate disutility. When entering the higher education system, let us name this universities for the rest of the paper, individuals have to decide on their time effort $e \in[0,1]$ devoted to learning, and consume the remaining time endowment, $1-e$, as first-period leisure. At the beginning of the second period individuals decide on their individual labor supply.

However, while entering the university neither a successful graduation nor an employment in the skilled labor sector afterwards is guaranteed. The probability $p$ to pass the educational process and to acquire an employment as skilled worker successfully, positively depends on the effort invested into education $e$, as higher educated people easier get higher paid jobs. Beside individual effort, the success probability also depends positively on the quality of the universities, being measured in this paper by public funding $E$ of the educational sector. In fact, public spending finances the overwhelming part of expenditure on educational institu-

\footnotetext{
${ }^{3}$ In fact, the mobility of skilled households can be seen as (an extreme) form of skilled labor supply elasticity in their papers, but still the unskilled cannot react to, e.g., tax rate changes.

${ }^{4}$ Implicitly, we assume that individuals already attended compulsory schooling.
} 
tions, accounting in 2004 for $75.7 \%$ respectively for $84.0 \%$ of overall expenditure in tertiary education on OECD average respectively on EU19 average. ${ }^{5}$

Therefore, we assume the probability function to be a concave function of both learning effort $e$ and public funding $E$, having both positive, but diminishing marginal productivities. ${ }^{6}$ Moreover, we assume that an increase in public funding (and consequently in the quality of the university) also increases the marginal productivity of each time unit invested. ${ }^{7}$

Accordingly, our human capital production function is given as probability function for entering the skilled sector

$$
p=p(e, E) \in[0,1)
$$

where no private effort at all, $e=0$, leads to remaining unskilled with certainty, consequently $p(0, E)=0$. A successful graduation alters the qualitative nature of labor from unskilled to skilled labor. Each skilled worker is supplied with one unit of human capital. ${ }^{8}$

Formally recapitulating the discussion above, we assume the probability function in equation (1) to have the following properties:

Assumption 1. The probability function for entering successfully the skilled sec-

${ }^{5}$ See OECD (2007), Indicator B3 and Table B3.2b.

${ }^{6}$ It might appear odd not to include private resource investment in the educational sector as determinant of the probability function into the model, because it accounts on average for 15 to 25 per cent of overall expenditure. However, including it makes the analysis very complicated on a technical level, whereas the main results should not change qualitatively as long as there is no perfect crowding-out in private and public investment. Therefore, we neglect these private spending, though this is a hard assumption.

${ }^{7}$ This assumption might be seen as analogon to complementarity between ability and educational investment, the latter being used, e.g, in Maldonado (2008) and Jacobs and Bovenberg (2008), which both generalize the Siamese-Twins-model by Bovenberg and Jacobs (2005).

${ }^{8}$ The assumption that a successful graduation provides each individual with one unit of human capital is made to simplify the model and to concentrate on the educational risk. A different formulation of the human capital production function includes learning effort, $e$, and public resources, $E$ as arguments: $h=h(e, E)$ with $h_{i}>0, h_{i i}<0, i=e, E$. 
tor has the following properties:

$$
\begin{array}{rlrl}
\frac{\partial p}{\partial e} & =p_{e}>0, & & \frac{\partial^{2} p}{\partial e^{2}}=p_{e e}<0 \\
\frac{\partial p}{\partial E} & =p_{E}>0, & & \frac{\partial^{2} p}{\partial E^{2}}=p_{E E}<0 \\
\frac{\partial^{2} p}{\partial e \partial E}=p_{e E}>0 & &
\end{array}
$$

The probability function in equation (1) mirrors some stylized facts and captures both the risk of failing in graduation from universities and the risk of getting no employment respectively only a low-paid job after graduation. The former risk fits into the category "input risk," as defined by Levhari and Weiss (1974), whereas the latter one mirrors "output risk" in their terminology. Both kinds of educational risk are highly of relevance: First, drop-out rates in, i.e., tertiary education are, in 2005, on average around 30\% (both in the OECD and the EU19), but range from $9 \%$ in Japan and $17 \%$ in Ireland to $46 \%$ in the US (OECD, 2007, pp. 63 and Table A3.6). Second, focusing on unemployment risk, this is with about $6 \%$ on OECD-average respectively $7 \%$ within the EU19 significant and even for graduates in tertiary education not negligible at 4\% (OECD, 2007, Tables A8.2a and $\mathrm{A} 8.4 \mathrm{a})$.

However, though investments in education cause risks, e.g. due to failure as discussed above or due to, i.e, technological change affecting the utilization of (specific) human capital as another source of output risk (Wildasin, 2000), learning effort and the quality of education have a mitigating effect on the magnitude of these risks, effecting the success probability directly. As a matter of fact, the drop-out risk is decreasing in learning effort. Higher educational attainment and a higher quality of education moreover have a tremendous effect on the output risk. The OECD (2007, pp.128) regards upper-secondary education as the minimum level in order to be competitive in the labor market and to obtain a satisfactory position. In fact, employment rates increase sharply in educational attainment, whereas in the last 15 years the unemployment risk of workers, who never tried to reach or failed in upper-secondary education, has been on average twice as large as for workers with a degree on the upper-secondary level and even triple as large as for graduates in tertiary education (OECD, 2007, Tables A8.2a to A8.4a). Dif- 
ferentiating for the level of educational attainment, these figures are also mirrored in unemployment rates of young non-students, which are then a good indicator of how higher education affects economic opportunities (OECD, 2007, pp. 331 and Table C4.3). Especially tertiary education provides a premium, here.

Based on these stylized facts, we will interpret the success probability as equivalent to educational opportunities, and, accordingly increasing educational opportunities therefore means increasing the success probability.

Comparing the modeling of (educational) risk in equation (1) and Assumption 1 to the modeling in most of the papers on (income) risk and publicly provided social insurance (i.e., Eaton and Rosen (1980b), Hamilton (1987), Anderberg and Andersson (2003)), which build on the seminal model by Levhari and Weiss (1974), there are some important differences. In Levhari-Weiss-type models risk is driven by an exogenous stochastic factor, whose effect on incomes is either enforced or mitigated by the level of education, a household acquires. Thus, first, the risk itself is exogenous, and the households can use either under- or overinvestment in education only as self-insurance device. Second, the government can provide social insurance by taxation, and it can grant subsidies to education in order to affect the self-insurance by the households - either by implementing indirect subsidies via capital taxation (Hamilton, 1987) or via direct control (being equal to direct subsidies) of education (Anderberg and Andersson, 2003). However, the government can, by its spending, neither affect the risk itself, nor do education subsidies have a (stand-alone) insurance effect.

In our model, following, e.g., Andersson and Konrad (2003b), the emergence of risk is determined endogenously by educational investment into learning effort. Hence, society rationally produces its risk. We think that in our context this modeling is reasonable as it mirrors better the stylized facts, discussed above. Moreover, we extend the analysis to allow for quality and funding of universities, determining the level of educational opportunities. Via this channel, the government can now affect directly the magnitude of risk in the economy by varying its public funding. Consequently, the government gains an additional insurance device. Note, that this would even be the case, if we allow for private resource investment, as long as public and private funding are not perfect substitutes.

At the beginning of the second period, those individuals who successfully 
passed the graduation and application process start working as skilled workers, while those who fail enter the labor market as unskilled workers. Assuming competitive labor markets, we are not able to deal directly with unemployment risk, being discussed in the stylized facts. However, an increasing wage gap between skilled and unskilled workers in perfect labor markets and increasing unemployment among unskilled ones in labor markets with some rigidities are driven by the same fundamental economic factors (i.e., Krugman (1995), Katz and Autor (1999)). Thus, our model applying a skill premium in wages in competitive markets can be seen as suitable approximation.

In the second period households are endowed with one divisible unit of time, which is divided between second-period leisure and labor supply. ${ }^{9}$ Total wage income is spent on total family consumption.

Following the major line of the literature, we assume that private insurance against educational risk is not available. This might be because of market failure due to moral hazard (Eaton and Rosen, 1980b), to adverse selection or to the fact that individuals are too young to write insurance contracts, when they decide on their human capital investment (Sinn, 1996). ${ }^{10}$

All individuals have identical preferences which are defined over leisure in period one and two, $l_{1}$ and $l_{2}$, and over total family consumption $C$ in period two. Thereby, family consumption includes (good) consumption by the child. Formally, the preferences are described by a von Neumann-Morgenstern expected utility function which is additively separable in its intertemporal components. Thus, we have

$$
\mathrm{E}[U]=U_{1}(1-e)+p(e, E) \cdot U_{2}\left(C_{H}, 1-H\right)+[1-p(e, E)] \cdot U_{2}\left(C_{L}, 1-L\right),
$$

where $H=1-l_{2 H}$ denotes labor supplied by a skilled worker in the second

\footnotetext{
${ }^{9}$ Because individuals decide about their working time in the second period, a different formulation for the human capital production function will not change our qualitative results. This is because the amount of human capital, an individual possesses, differs from the amount offered on the labor market. Including a human capital production function as described in footnote 8 just means that we have two sources to influence the supplied amount of human capital which work in the same direction.

${ }^{10}$ See, e.g., Andersson and Konrad (2003a) for an opposing view and some discussion of this assumption.
} 
period, and $L=1-l_{2 L}$ denotes labor supplied by an unskilled worker in the second period. ${ }^{11}$ In order to ensure an interior solution, especially for the learning effort $e=1-l_{1}$, we assume that the utility function meets the following Inada conditions:

Assumption 2. First and second period utility exhibits the following properties:

$$
\begin{array}{rlrl}
\frac{\partial U_{i}}{\partial l_{i}}, \frac{\partial U_{2}}{\partial C}>0, \frac{\partial^{2} U_{i}}{\partial l_{i}^{2}}, \frac{\partial^{2} U_{2}}{\partial C^{2}}<0 & i=1,2 \\
\lim _{l_{i} \rightarrow 0} \frac{\partial U_{i}}{\partial l_{i}}=\lim _{C \rightarrow 0} \frac{\partial U_{2}}{\partial C} \rightarrow \infty, \lim _{l_{i} \rightarrow 1} \frac{\partial U_{i}}{\partial l_{i}}=\lim _{C \rightarrow \infty} \frac{\partial U_{2}}{\partial C}=0 & i=1,2 .
\end{array}
$$

Wages for both skill groups are exogenously given and denoted by $w_{H}$ and $w_{L}$ respectively and the skill premium in wages equals $w_{H}-w_{L}>0 .{ }^{12}$ The government uses a linear (indirectly progressive) income tax scheme consisting of a tax rate $t$ and a lump-sum transfer $T$. Moreover, higher education is subject to tuition fees. ${ }^{13}$ Hereby, the fiction is that these fees are due at entering the education sector, but are pre-financed by the government via a compulsory public credit. Thus, there are no real payments in the first period of life. In the second period, the repayment is settled in terms of a contingent loan, whereby we assume in this model that only households, which successfully entered the skilled sector, are liable to repay a fixed amount $f_{B}$, being independent of income.

Labeling our loan system is a bit difficult, because, in the literature concerning graduate taxation and income-contingent loans, there are various definitions and some confusion to be found. According to Jacobs (2002, Section 2), these governmental instruments can be distinguished as follows: Income-contingent loans have to be repaid by graduates, when they start to work and if their income exceeds a kick-in level. The repayment is a fraction of earned income, but the sum of all repayments is determined by the loan received (plus risk-adjusted interest). A graduate tax is very similar, but the repayments are not earmarked to the initial

${ }^{11}$ Subscripts $H$ and $L$ denote the respective values for the different skill groups.

${ }^{12}$ Assuming exogenous wages can, i.e., be justified by focusing on a small open economy with two sectors.

${ }^{13}$ Note that we do not require the tuition fees to match public expenses for higher education. Instead, the government can, e.g., use a mix of instruments to finance higher education or can spend tuition fees partly outside the education sector. 
subsidy received. In fact, a graduate tax is a progressive labor tax, which graduates have to pay until they retire.

Our loan repayment $f_{B}$ is, instead, like a public credit contract, where the repayment is conditioned on successful graduation into the skilled sector. Hence, our loan system is rather skill-contingent than income contingent. However, the skill-contingency turns into an income-contingent loan, if one (i) neglects annual repayments to be proportional to earned income (which is justifiable in a two period model) and (ii) assumes that in our model only households which successfully graduated and work as skilled workers have an income above the kick-in threshold, high enough to repay the loan $f_{B}$.

In the following we will use the term 'skill-specific tuition fees' as short-cut for the combination of tuition fees and their deferred payment via skill-contingent loans. The alternative wording 'graduate (income) tax' - which seems to be very appealing at first glance - might be misleading, because the payment $f_{B}$ does not depend on skilled income, but only on the fact that one is employed in the skilled sector.

As earning income, payment of taxes, and the payment of skill-specific tuition fees take place within the same period, we assume that these fees can be deducted as income-related expenses against taxable income. ${ }^{14}$ The budget constraint of a skilled household can then be written as

$$
C_{H}=(1-t) \cdot\left[w_{H} \cdot H-f_{B}\right]+T,
$$

whereas consumption of an unskilled household is given by

$$
C_{L}=(1-t) \cdot w_{L} \cdot L+T
$$

The educational risk is assumed to be idiosyncratic, hence, there are ex-post $p(e, E)$ skilled workers and $1-p(e, E)$ unskilled ones in each generation. The

\footnotetext{
${ }^{14}$ Deducting tuition fees as expenses appears to be odd at first glance, because mostly they cannot. However, the reason for the latter is that, usually, tuition fees are paid in a period, where students do not earn taxable income, and bringing forward these expenses is not allowed in most tax codes, see, e.g., the German EStG. Moreover, our assumption is not crucial, because it is straightforward to show that neither the analysis nor any result will change in our model, if tuition fees are not tax-deductable.
} 
government uses its instruments in order to maximize the utility of a representative steady-state generation. Consequently, the government faces a trade-off between efficient financing of public expenditure and optimal redistribution between successful and unsuccessful students as well as optimal insurance against the risk of education.

In a nutshell, the timing structure and the model can be summarized as follows: First, the benevolent government decides on public funding of the educational sector and on the tax instruments. ${ }^{15}$ Second, the young generation will choose the learning effort given the wages and the governmental decisions. This in turn determines the success probability $p(e, E)$, and with it the fraction of skilled and unskilled workers. At the beginning of the second period each individual knows whether it graduated into the skilled sector or failed and will then decide on its labor supply. In the following, we will solve the model by backward induction.

\section{Household Behavior}

The complete decision problem of a representative household can be described by the following maximization problem:

$$
\begin{aligned}
\max _{\left\{e, H, C_{H}, L, C_{L}\right\}} \mathrm{E}[U] & =U_{1}(1-e)+p(e, E) \cdot U_{2}\left(C_{H}, 1-H\right) \\
& +[1-p(e, E)] \cdot U_{2}\left(C_{L}, 1-L\right) \text { s.t. (3) and (4) }
\end{aligned}
$$

Substitution of (3) and (4) for $C_{H}$ and $C_{L}$ in (5) yields the following first order conditions:

$$
\begin{aligned}
\frac{\partial \mathrm{E}[U]}{\partial H} & =U_{2 C}\left(C_{H}, 1-H\right) \cdot(1-t) w_{H}-U_{2 l_{2}}\left(C_{H}, 1-H\right)=0 \\
\frac{\partial \mathrm{E}[U]}{\partial L} & =U_{2 C}\left(C_{L}, 1-L\right) \cdot(1-t) w_{L}-U_{2 l_{2}}\left(C_{L}, 1-L\right)=0 \\
\frac{\partial \mathrm{E}[U]}{\partial e} & =-U_{1 l_{1}}(1-e)+p_{e} \cdot\left[U_{2}\left(C_{H}, 1-H\right)-U_{2}\left(C_{L}, 1-L\right)\right]=0 .
\end{aligned}
$$

${ }^{15}$ We thereby assume that the government can credibly commit to its chosen tax instruments, and we do not consider any hold-up and time-consistency problem. Moreover, we do not focus on extortionary Leviathan governments. See, i.e., Andersson and Konrad (2003b) for these issues in a related context. 
The system of first order conditions (6) to (8) is block recursive such that optimal labor supply $H^{*}, L^{*}$ and with it optimal consumption $C_{H}^{*}, C_{L}^{*}$ are separately defined by (6) and (7) respective. ${ }^{16}$ Note that optimal consumption and labor supply of the respective skill group is conditional on the policy mix used by the government $(t, T)$ as well as on the respective wage rate $w_{H}, w_{L}$. Additionally, skill-specific tuition fees $f_{B}$ are only relevant for labor supply and consumption of skilled workers. Inserting optimal labor supply and consumption into the second period utility function gives the indirect utility function for both types of workers: $V^{H}=U_{2}\left(C_{H}^{*}, 1-H^{*}\right), V^{L}=U_{2}\left(C_{L}^{*}, 1-L^{*}\right)$. Using the respective indirect utility functions $V^{H}$ and $V^{L}$ in (8) results in the optimal effort $e^{*}=e\left(t, T, f_{B}, E, w_{H}, w_{L}\right)$. Evaluating first period utility at the optimal effort $e^{*}$ gives the first period indirect utility function $V=U_{1}\left(1-e^{*}\right)$.

Given the properties of the utility functions stated in assumption 2 and the block recursive form of the first order conditions, it is sufficient to check the second order conditions of (5) for each separate variable:

$$
\begin{aligned}
\left.\frac{\partial^{2} \mathrm{E}[U]}{\partial H^{2}}\right|_{H=H^{*}} & =S O C(H) \\
& =U_{2 C C}(1-t)^{2} w_{H}^{2}-2 U_{2 C l_{2}}(1-t) w_{H}+U_{2 l_{2} l_{2}}<0, \\
& =S O C(L) \\
& =U_{2 C C}(1-t)^{2} w_{L}^{2}-2 U_{2 C l_{2}}(1-t) w_{L}+U_{2 l_{2} l_{2}}<0, \\
\left.\frac{\partial^{2} \mathrm{E}[U]}{\partial e^{2}}\right|_{e=e^{*}} & =S O C(e) \\
& =U_{1 l_{1} l_{1}}+p_{e e}\left(V^{H}-V^{L}\right)<0 .
\end{aligned}
$$

The inequality in equation (11) is given by decreasing marginal utility of leisure, and decreasing marginal productivity of learning, and by the fact that a skilled worker must have higher utility in the second period than an unskilled one, $V^{H}>V^{L}$, because else there will be no learning effort at all.

In the next sections we derive the optimal policy mix. For that reason, we need to derive the comparative statics of the individual choice variables with respect to

\footnotetext{
${ }^{16}$ Throughout the paper, asterisks denote optimal values. To simplify the notation, we drop the functional arguments $t, T, f_{B}, w_{H}, w_{L}$, when this causes no confusion.
} 
the different instruments. We start by calculating the comparative statics of the labor supply of both skill groups:

$$
\begin{aligned}
\frac{\partial H^{*}}{\partial t} & =-\frac{-U_{2 C C}(1-t) w_{H}^{2}+\left(U_{2 C l_{2}}-U_{2 C}\right) \cdot w_{H}}{S O C(H)} \lessgtr 0, \\
\frac{\partial H^{*}}{\partial T} & =-\frac{\partial H^{*}}{\partial f_{B}} \cdot \frac{1}{1-t}=-\frac{U_{2 C C}(1-t) w_{H}-U_{2 C l_{2}}}{S O C(H)}<0, \\
\frac{\partial L^{*}}{\partial t} & =-\frac{-U_{2 C C}(1-t) w_{L}^{2}+\left(U_{2 C l_{2}}-U_{2 C}\right) \cdot w_{L}}{S O C(L)} \lessgtr 0, \\
\frac{\partial L^{*}}{\partial T} & =-\frac{U_{2 C C}(1-t) w_{L}-U_{2 C l_{2}}}{S O C(L)}<0,
\end{aligned}
$$

where we have assumed that leisure is a normal good. Assuming the substitution effect to dominate, we avoid backward bending labor supply, thus $\frac{\partial H}{\partial t}, \frac{\partial L}{\partial t}<0$.

By the very same analysis we get comparative static results for the learning effort $e^{*}$ with respect to the lump-sum transfer $T$ :

$$
\frac{\partial e^{*}}{\partial T}=-\frac{p_{e} \cdot\left(\alpha^{H}-\alpha^{L}\right)}{S O C(e)}<0,
$$

with $\alpha^{j}=\frac{\partial V^{j}}{\partial C}>0, j=H, L$ denoting the marginal utility of income. The inequality in equation (12) stems from the fact that we assume agent monotonicity (Mirrlees, 1976) to hold. This implies that a skilled worker always commands a higher income than an unskilled worker, and hence $\alpha^{H}<\alpha^{L}$. The intuition is straightforward: any increase in lump-sum income $T$ decreases the learning intensity $e$, because an educational degree gets marginally less attractive.

An increase in skill-specific fees changes the learning effort according to

$$
\frac{\partial e^{*}}{\partial f_{B}}=\frac{p_{e} \cdot \alpha^{H} \cdot(1-t)}{S O C(e)}<0
$$

while increased public spending in education $E$ changes the effort according to

$$
\frac{\partial e^{*}}{\partial E}=-\frac{p_{e E} \cdot\left(V^{H}-V^{L}\right)}{S O C(e)}>0 .
$$

Learning effort is unambiguously reduced if the skill-specific tuition fees rise be- 
cause this directly reduces the return to education and creates a negative substitution effect, whilst increased spending in education increases the productivity of learning, $p_{e E}>0$, and therefore learning effort.

Contrary to these effects, the effect of an increase in the wage tax $t$ is less clear. Increasing ceteris paribus the tax burden on skilled wage income, decreases learning effort, because the returns to schooling decrease. Increasing ceteris paribus the wage tax for unskilled workers increases the returns to schooling, and increases the learning intensity. Combining both effects, we end up with

$$
\frac{\partial e^{*}}{\partial t}=-\frac{p_{e}\left[\alpha^{L} \cdot w_{L} L^{*}-\alpha^{H} \cdot\left(w_{H} H^{*}-f_{B}\right)\right]}{S O C(e)} .
$$

If labor supply of skilled workers is not significantly higher than labor supply of unskilled ones, and given the single crossing property, an increase in the tax rate increases the learning intensity, because $\alpha^{L} \cdot w_{L} L^{*}>\alpha^{H} \cdot\left(w_{H} H^{*}-f_{B}\right)$. The intuition is twofold: First, our assumptions imply that the taxation of unskilled outweighs taxation of skilled, and second, a higher tax rate decreases the income risk of time investment in education by providing an insurance effect via decreasing the variance in after-tax incomes.

Evaluating the expected utility function in (5) at the optimal labor supplies, $H^{*}, L^{*}$, and the optimal learning effort, $e^{*}$, the indirect expected utility function of the household can be written as

$\mathrm{E}\left[V^{*}\left(t, T, f_{B}, E\right)\right]=V\left(t, T, f_{B}, E\right)+p\left(e^{*}, E\right) \cdot V^{H}\left(t, T, f_{B}\right)+\left[1-p\left(e^{*}, E\right)\right] \cdot V^{L}(t, T)$.

It is important to note that $\mathrm{E}\left[V^{*}\right]$ is a function of the policy mix chosen by the government. This policy mix is exogenously given for the households. By using the envelope-theorem we can derive the marginal impact of a policy change on 
the expected utility of household, which will be useful later on:

$$
\begin{aligned}
& \frac{\partial \mathrm{E}\left[V^{*}\right]}{\partial f_{B}}=-p^{*} \cdot \alpha^{H} \cdot(1-t)<0, \\
& \frac{\partial \mathrm{E}\left[V^{*}\right]}{\partial T}=p^{*} \cdot \alpha^{H}+\left(1-p^{*}\right) \cdot \alpha^{L}>0 \\
& \frac{\partial \mathrm{E}\left[V^{*}\right]}{\partial t}=-p^{*} \cdot \alpha^{H} \cdot\left[w_{H} H^{*}-f_{B}\right]-\left(1-p^{*}\right) \cdot \alpha^{L} \cdot w_{L} L^{*}<0 \\
& \frac{\partial \mathrm{E}\left[V^{*}\right]}{\partial E}=p_{E}^{*} \cdot\left[V^{H}-V^{L}\right]>0 .
\end{aligned}
$$

\section{First-best as Benchmark}

Before we analyze the optimal public policy in a Second-best setting, as described in section 3, we establish the First-best solution as a benchmark. This allows later on to examine potential shifts in optimal insuring strategies and to answer the question, in which cases income insurance respectively increased educational opportunities have more importance.

The First-best allocation can be characterized by

$\max _{e, E, C_{H}, H, C_{L}, L} U_{1}(1-e)+p(e, E) \cdot V^{H}\left(C_{H}, 1-H\right)+[1-p(e, E)] \cdot V^{L}\left(C_{L}, 1-L\right)$

subject to the resource constraint

$$
E+p(e, E) \cdot C_{H}+[1-p(e, E)] \cdot C_{L}=p(e, E) \cdot w_{H} H+[1-p(e, E)] \cdot w_{L} L .
$$

Note that in a First-best the government not only chooses consumption $C_{j}$ and labor supply $Z_{j}, Z_{j}, j=H, L$, for skilled and unskilled households, but also fully controls learning effort $e$ and real educational investment $E$. 
The first order conditions are

$$
\begin{aligned}
\frac{\partial \mathcal{L}}{\partial e}= & -U_{1 l_{1}}(1-e)+p_{e} \cdot\left[V^{H}-V^{L}\right] \\
& +\lambda \cdot p_{e} \cdot\left[\left(w_{H} H-C_{H}\right)-\left(w_{L} L-C_{L}\right)\right]=0, \\
\frac{\partial \mathcal{L}}{\partial E}= & p_{E} \cdot\left[V^{H}-V^{L}\right] \\
& +\lambda \cdot p_{E} \cdot\left[\left(w_{H} H-C_{H}\right)-\left(w_{L} L-C_{L}\right)-\frac{1}{p_{E}}\right]=0, \\
\frac{\partial \mathcal{L}}{\partial C_{H}}= & p(e, E) \cdot\left(\alpha^{H}-\lambda\right)=0, \\
\frac{\partial \mathcal{L}}{\partial H}= & p(e, E) \cdot\left(\lambda w_{H}-U_{2 l_{2}}^{H}\right)=0 \\
\frac{\partial \mathcal{L}}{\partial C_{L}}= & {[1-p(e, E)] \cdot\left(\alpha^{L}-\lambda\right)=0, } \\
\frac{\partial \mathcal{L}}{\partial L}= & {[1-p(e, E)] \cdot\left(\lambda w_{L}-U_{2 l_{2}}^{L}\right)=0, }
\end{aligned}
$$

where $\lambda$ represents the Lagrangian multiplier and, according to section $4, \alpha^{j}$ equals marginal utility of income in the respective skill groups $j=H, L$.

From equations (25) and (27) follows that

$$
\alpha^{H}=\lambda=\alpha^{L}=\alpha,
$$

thus all households have the same marginal utility of income. Combining next (26) and (28) results in

$$
\frac{U_{2 l_{2}}^{H}}{U_{2 l_{2}}^{L}}=\frac{w_{H}}{w_{L}}>1,
$$

implying $U_{2 l_{2}}^{H}>U_{2 l_{2}}^{L}$. Skilled households have a higher marginal utility of leisure in the second period and are therefore assumed to work more than the unskilled, $H^{F B}>L^{F B} \cdot{ }^{17}$ This appears reasonable from an efficiency point of view, because the skilled are more productive. These results then suggest on the one hand that the government provides full income insurance, in sense of equalized marginal utilities of consumption/income, but on the other hand that the skill premium, measured in utility, $V^{H}-V^{L}$ turns negative. These are the most important differ-

${ }^{17}$ Throughout the paper, the superscript $F B$ will characterize the value of a variable in the First-best solution. 
ences to a laissez-faire economy or to a Second-best solution, and they are driven by the fact, that the social planer (the government) can control learning effort perfectly in a First-best approach. If there is moral hazard in learning, a positive skill premium in utility is absolutely necessary in order to induce learning effort - else there would not be any skilled worker in the economy, because $p(0, E)=0$.

In the special case of an additively separable second period utility function, all these results get crystal clear, because then they imply unquestionable $C_{H}^{F B}=$ $C_{L}^{F B}=C^{F B}$, but $H^{F B}>L^{F B}$ and, consequently, First-best optimal leisure $1-H^{F B}<1-L^{F B}$. Therefore, we end up with $V^{H}-V^{L}<0$, giving the unskilled the higher second period (and overall) utility.

Note also that all these conditions are independent of learning effort and the quality of the educational system, thus they must hold irrespectively of the level of $E$.

Given the results for optimal consumption and labor supply in the second period, First-best efficient learning effort then balances marginal disutility of forgone first-period leisure $\left(U_{1 l_{1}}\right)$ and the second-period welfare loss by an increased number of skilled households (due to $V^{H}-V^{L}<0$ ) on the one hand and tax revenue gains by an increased number of skilled households on the other hand. Hereby, we interpret $T_{j}=\left(w_{j} Z_{j}-C_{j}\right), Z_{j}, j=H, L$, as lump-sum tax payment of a household of skill group $j$. As the first line in equation (23) is negative and $\lambda=\alpha>0$ as well as $p_{e}>0$, the squared bracket in the second line of (23) has to be positive. Accordingly, a First-best optimum implies $T_{H}>T_{L}$.

Optimal public spending $E$ on the quality of the educational sector is determined by a similar trade-off between welfare gains: public spending itself is costly and an increased success probability $\left(p_{E}>0\right)$ and therefore an increased number of skilled households decrease ceteris paribus welfare, because $V^{H}-V^{L}<0$. However, an increase in skilled workers also increases the resources available for redistribution.

By applying the resource constraint (22) and $T_{H}>T_{L}$, we can derive

$$
T_{H}>E^{F B}>T_{L}
$$

Moreover, from rearranging (24), we obtain the First-best investment in public 
education as

$$
E^{F B}=p^{F B} \cdot \epsilon_{p E} \cdot \frac{V^{H}-V^{L}}{\alpha}+p^{F B} \cdot \epsilon_{p E} \cdot\left[T_{H}-T_{L}\right],
$$

where $\epsilon_{p E}$ is the elasticity of the probability function $p(e, E)$ with respect to a variation of $E$. $E^{F B}$ is decreasing in the negative skill premium $V^{H}-V^{L}$, but increasing in the additional resources available for redistribution $T_{H}-T_{L}{ }^{18}$

We conclude:

Proposition 1. In a First-best solution, the government provides in any case full insurance in income by ensuring equalized marginal utility of income respectively consumption across skill types. If optimal educational investment is relatively low $\left(E<p^{F B} \cdot T_{H}\right)$, there are direct resource (income) transfers from the skilled to the unskilled households $\left(T_{L}<0\right)$.

In a nutshell, income insurance is of major importance relative to increasing educational opportunities, measured by an increase in the success probability $p(e, E)$. In the following sections, we will now characterize Second-best efficient policies and then compare the results to the First-best benchmark.

\section{Public Policy in a Second-best World}

The benevolent government again aims to maximize social welfare. Therefore, it can influence the quality of the education system by choosing the public spending in education $E$, and it can grant a lump-sum transfer $T$, but it can no longer control private learning effort directly. Overall expenditure $E+T$ must be financed by deferred tuition fees in terms of skill-contingent loans $f_{B}$, and by a proportional wage tax at rate $t$. We should stress again that the educational risk is idiosyncratic, and therefore there is no aggregate risk. From the government's perspective, there are $p\left(e^{*}, E\right)$ skilled workers supplying $p^{*} \cdot H^{*}$ efficiency units of skilled labor and $\left[1-p\left(e^{*}, E\right)\right]$ unskilled workers supplying $\left(1-p^{*}\right) \cdot L^{*}$ efficiency units of unskilled

${ }^{18}$ In principle there can be a corner solution $E^{F B}=0$, where the government would like to have a negative resource investment into education, if either the negative utility premium $V^{H}-V^{L}$ is too large or the positive gain in tax revenue $T_{H}-T_{L}$ is too small. We are going, however, to focus on inner solutions, where $E^{F B} \geq 0$ is optimal. 
labor.

Thus, the governmental budget constraint can be written as

$$
E+T=p^{*} \cdot\left[t w_{H} H^{*}+(1-t) f_{B}\right]+\left(1-p^{*}\right) \cdot t w_{L} L^{*}
$$

Using $E$, the government can directly influence the percentage of skilled workers. Using the tax instruments, it can redistribute income between skilled and unskilled households, which affects indirectly the shares of skilled and unskilled workers via incentives for learning effort. Both skill-specific tuition fees and the wage tax $t$ provide another partial insurance against income fluctuations, and therefore against the educational risk.

We are now able to state some first results. Let us assume for a moment that all expenditure $E$ is financed by a lump-sum tax $T<0$.

Corollary 1. It is not optimal to finance the education system only by a (uniform) lump-sum tax $T<0$. The introduction of (i) (deferred) skill-specific tuition fees or (ii) a wage tax while reducing the lump-sum tax burden such that the spending level E remains constant is always welfare improving.

Proof. Assume that initially $E=-T$ and $t=f_{B}=0$ hold. Next we introduce either skill-specific tuition fees $f_{B}>0$ or a wage tax $t>0$, while simultaneously reducing the lump-sum tax, such that in both cases total spending remains constant $d E=0$. Implicit differentiation of (33) with respect to $f_{B}$ and $t$ yields:

$$
\begin{aligned}
& \left.\frac{\partial T}{\partial f_{B}}\right|_{t=f_{B}=d E=0}=p\left(e^{*}, E\right) \\
& \left.\frac{\partial T}{\partial t}\right|_{t=f_{B}=d E=0}=p\left(e^{*}, E\right) \cdot w_{H} H^{*}+\left[1-p\left(e^{*}, E\right)\right] \cdot w_{L} L^{*}
\end{aligned}
$$

The welfare effect of introducing skill-specific fees, respectively a wage tax, can then be derived by taking the derivative of (16) with respect to $f_{B}$, respectively to 
$t$, and observing that $T$ will change according to (34) and (35):

$$
\begin{aligned}
\left.\frac{d \mathrm{E}\left[V^{*}\right]}{d f_{B}}\right|_{t=f_{B}=d E=0} & =\frac{\partial \mathrm{E}\left[V^{*}\right]}{\partial f_{B}}+\left.\frac{\partial \mathrm{E}\left[V^{*}\right]}{\partial T} \frac{\partial T}{\partial f_{B}}\right|_{t=f_{B}=d E=0} \\
& =p^{*} \cdot\left(1-p^{*}\right) \cdot\left(\alpha^{L}-\alpha^{H}\right)>0 \\
\left.\frac{d \mathrm{E}\left[V^{*}\right]}{d t}\right|_{t=f_{B}=d E=0} & =\frac{\partial \mathrm{E}\left[V^{*}\right]}{\partial t}+\left.\frac{\partial \mathrm{E}\left[V^{*}\right]}{\partial T} \frac{\partial T}{\partial t}\right|_{t=f_{B}=d E=0} \\
& =p^{*} \cdot\left(1-p^{*}\right) \cdot\left(w_{H} \cdot H^{*}-w_{L} L^{*}\right)\left(\alpha^{L}-\alpha^{H}\right)>0
\end{aligned}
$$

whereby we have used the Envelope results in equations (17) to (19).

Financing public expenditure partly by skill-specific tuition fees creates not only an income effect on learning intensity and on labor supply, but also gives rise to a substitution effect in learning, because being skilled gets relatively less attractive. However, around $f_{B}=0$, for the first euro of skill-specific fees, the negative effect of this distortion is overcompensated by the fact that now the skilled workers pay more for their education than unskilled ones, who failed. As risk aversion and inequality aversion are just two sides of the same coin, society appreciates a more equal income distribution because of decreasing marginal utility of income. The latter effect of skill-specific tuition fees therefore implies a welfare enhancing redistribution from high income skilled workers to low income unskilled workers.

Introducing a wage tax does not affect the relative wage premium $w_{H} / w_{L}$, but still has an ambiguous (income) effect on the learning intensity, and creates distortions in both skilled and unskilled labor supply. However, the wage tax simultaneously reduces the income risk of educational effort on the individual level, because the gap between skilled and unskilled income is narrowed, and achieves a welfare enhancing redistribution of incomes from a society's point of view. Starting at $t=0$, the insurance effect (in combination with the redistribution) dominates the induced distortions and overcompensates the negative incentive effects on labor supply.

Hence, the effect of a positive wage tax can be seen as reproducing or extending the seminal results of Eaton and Rosen $(1980 \mathrm{a}, \mathrm{b})$ in our model of educational risk.

The questions we seek to answer now are: (i) What is the optimal combination 
of wage taxes, lump-sum elements and (deferred) skill-specific tuition fees in such an environment? (ii) What determines the optimal values of the tax rate $t$ and the fee $f_{B}$ ? (iii) Does, in a Second-best world, income insurance still matter more than educational opportunities?

\section{Optimal Taxation and Skill-specific Tuition Fees}

The government seeks to maximize social welfare $\mathrm{E}\left[V^{*}\left(E, f_{B}, t, T\right)\right]$ by choosing public spending in education $E$ as well as the financing scheme $f_{B}, t$ and $T$. Formally, the problem can be written as:

$$
\max _{\left\{E, f_{B}, t, T\right\}} \mathrm{E}\left[V^{*}\left(E, f_{B}, t, T\right)\right] \text { s.t. }\left[t w_{H} H^{*}+(1-t) f_{B}\right] p+t \cdot w_{L} L^{*}(1-p)=E+T
$$

Note that the government takes the optimal choice of households as granted and anticipates the reaction of households while making its choice of the policy mix. Forming the Lagrangian, $\mathcal{L}$, and introducing the Lagrange multiplier, $\lambda$, first order conditions read as follows:

$$
\begin{aligned}
\frac{\partial \mathcal{L}}{\partial f_{B}} & =-p^{*} \cdot \alpha^{H} \cdot(1-t)+\lambda\left(p^{*}(1-t)+p^{*} t w_{H} \frac{\partial H^{*}}{\partial f_{B}}\right) \\
& +\lambda\left[t w_{H} H^{*}+(1-t) f_{B}-t w_{L} L^{*}\right] p_{e}^{*} \frac{\partial e^{*}}{\partial f_{B}}=0 \\
\frac{\partial \mathcal{L}}{\partial T} & =p^{*} \alpha^{H}+\left(1-p^{*}\right) \alpha^{L}+\lambda\left(t\left[p^{*} w_{H} \frac{\partial H^{*}}{\partial T}+\left(1-p^{*}\right) w_{L} \frac{\partial L^{*}}{\partial T}\right]-1\right) \\
& +\lambda\left[t w_{H} H^{*}+(1-t) f_{B}-t w_{L} L^{*}\right] p_{e}^{*} \frac{\partial e^{*}}{\partial T}=0 \\
\frac{\partial \mathcal{L}}{\partial t} & =-p^{*} \alpha^{H} \cdot\left(w_{H} H^{*}-f_{B}\right)-\left(1-p^{*}\right) \alpha^{L} w_{L} L^{*}+\lambda \cdot p^{*} t w_{H} \frac{\partial H^{*}}{\partial t} \\
& +\lambda\left(\left(1-p^{*}\right) t w_{L} \frac{\partial L^{*}}{\partial t}+\left[t w_{H} H^{*}+(1-t) f_{B}-t w_{L} L^{*}\right] p_{e}^{*} \frac{\partial e^{*}}{\partial t}\right) \\
& +\lambda\left(p^{*}\left[w_{H} H^{*}-f_{B}\right]+\left[1-p^{*}\right] w_{L} L^{*}\right)=0 \\
\frac{\partial \mathcal{L}}{\partial E} & =p_{E}^{*}\left[V^{H}-V^{L}\right] \\
& +\lambda\left(\left[t w_{H} H^{*}+(1-t) f_{B}-t w_{L} L^{*}\right]\left[p_{e}^{*} \frac{\partial e^{*}}{\partial E}+p_{E}^{*}\right]-1\right)=0
\end{aligned}
$$


In subsection 7.1, we are first going to derive the optimal tax and education policy, if skill-specific tuition fees are not available. In subsection 7.2, we then broaden the analysis to the full set of instruments and show that the importance of educational opportunities is even more strengthened.

\subsection{Optimal Tax Policy Without a Fee-system}

We start first with the case, where the government has limited information and cannot implement skill-specific tuition fees. If so, FOC (39) is to be canceled and the parameter $f_{B}$ is equal to zero throughout equations (40) to (42).

Then, let us define the net social marginal value of income, (including the income effects on the tax base) of a household of type $j$ as

$$
b^{j}=\frac{\alpha^{j}}{\lambda}+t \cdot w_{j} \cdot Z_{j}^{*} \cdot \frac{\partial Z_{j}}{\partial T}+t \cdot\left(w_{H} \cdot H^{*}-w_{L} \cdot L^{*}\right) \cdot p_{e} \cdot \frac{\partial e}{\partial T}, \quad j=H, L,
$$

where $Z_{j}=H, L$ for $j=H, L$. The second summand on the RHS of (43) represents the loss in tax revenue due to an income-effect induced decrease in labor supply and the third summand incorporates the revenue effect from taxing the skill premium, when the households adjusts its learning effort and therefore its probability of getting employed as a skilled worker.

From equation (43), the expected net social marginal value of income is given by

$$
\begin{aligned}
\bar{b}= & \frac{p^{*} \cdot \alpha^{H}+\left(1-p^{*}\right) \cdot \alpha^{L}}{\lambda}+p^{*} \cdot t \cdot w_{H} \cdot H^{*} \cdot \frac{\partial H}{\partial T} \\
& +\left(1-p^{*}\right) \cdot t \cdot w_{L} \cdot L^{*} \cdot \frac{\partial L}{\partial T}+t \cdot\left(w_{H} \cdot H^{*}-w_{L} \cdot L^{*}\right) \cdot p_{e} \cdot \frac{\partial e}{\partial T} .
\end{aligned}
$$

Slightly rearranging FOC (40) and inserting the definition of $\bar{b}$ from equation (44), it is straightforward to show that for the expected net social marginal value of income it must be

$$
\bar{b}=1
$$

Next, we define the insurance characteristic as the negatively normalized covariance of net social marginal value of income $b^{j}$ and labor income $w_{j} \cdot Z_{j}$, being 
analogous to Feldstein's distributional characteristic and measuring society's concern of avoiding risk, hence, the insurance effect:

$$
\chi=-\frac{\operatorname{Cov}\left(b^{j}, w_{j} \cdot Z_{j}\right)}{\bar{b} \cdot\left(p^{*} \cdot w_{H} \cdot H^{*}+\left(1-p^{*}\right) \cdot w_{L} \cdot L^{*}\right)}>0
$$

being positive, because the social net marginal value of income is decreasing in income.

Moreover, we define

$$
\begin{aligned}
\bar{\epsilon}_{H H} & =\frac{p^{*} \cdot w_{H} \cdot H^{*}}{p^{*} \cdot w_{H} \cdot H^{*}+\left(1-p^{*}\right) \cdot w_{L} \cdot L^{*}} \cdot \frac{(1-t) w_{H}}{H^{*}} \cdot S_{H H}>0, \\
\bar{\epsilon}_{L L} & =\frac{\left(1-p^{*}\right) \cdot w_{L} \cdot L^{*}}{p^{*} \cdot w_{H} \cdot H^{*}+\left(1-p^{*}\right) \cdot w_{L} \cdot L^{*}} \cdot \frac{(1-t) w_{L}}{L^{*}} \cdot S_{L L}>0,
\end{aligned}
$$

as weighted compensated elasticities of labor supply with respect to its net wage, where $S_{j j}>0$ represents the substitution effect in labor supply $Z_{j}$. The weights are the share of skilled respectively unskilled labor income in aggregate labor income.

The compensated elasticity of learning effort with respect to a change in the expected net wage $(1-t) \bar{w}$ is displayed as

$$
\epsilon_{e \bar{w}}=\frac{(1-t) \bar{w}}{e} \cdot S_{e \bar{w}}
$$

where $\bar{w}=p^{*} \cdot w_{H}+\left(1-p^{*}\right) \cdot w_{L}$.

Applying equations (45) to (49), some covariance rules and the Slutskydecomposition, FOC (41) can be transformed in order to receive ${ }^{19}$

$$
\frac{t}{1-t}=\frac{\chi}{\bar{\epsilon}_{H H}+\bar{\epsilon}_{L L}+\frac{p^{*}\left(w_{H} \cdot H^{*}-w_{L} \cdot L^{*}\right)}{p^{*} \cdot w_{H} \cdot H^{*}+\left(1-p^{*}\right) \cdot w_{L} \cdot L^{*}} \cdot \epsilon_{p e} \cdot\left[\epsilon_{e \bar{w}}-\psi \cdot \eta_{e T}\right]} \geq 0,
$$

where $\epsilon_{p e}>0$ is the elasticity of the probability function $p(e, E)$ concerning a change in learning effort $e, \psi=\frac{\operatorname{Cov}\left(w_{j}, Z_{j}\right)}{\bar{w} \cdot\left[p^{*} \cdot H+\left(1-p^{*}\right) \cdot L\right]}>0, j=H, L$, is the coefficient of correlation of labor supply and wages, being positive as long as labor supply is not backward-bending, and $\eta_{e T}=\frac{(1-t) \cdot \bar{w} \cdot \bar{Z}}{e} \cdot \frac{\partial e}{\partial T}<0$ is the income elasticity of

${ }^{19}$ See Appendix 9.1 for an explicit derivation of equation (50). 
learning effort with respect to a change in expected net wage income.

As expected, the optimal labor tax rate is increasing in society's concern for insurance $\chi$ and the only role of taxation is to insure against educational risk, because the tax rate would be zero, if the insurance characteristics vanishes ( $\chi=$ $0)$. Furthermore, the tax rate is decreasing in induced distortions in skilled and unskilled labor supply, measured by the elasticities $\bar{\epsilon}_{H H}$ and $\bar{\epsilon}_{L L}$.

Last, but not least, wage taxation has a negative effect on compensated investment in learning, as ${ }^{20}$

$$
\epsilon_{e \bar{w}}-\psi \cdot \eta_{e T}>0
$$

This effect translates via $\epsilon_{p e}$ in a change in educational opportunities and, weighted by the expected skill premium in wages (relative to expected income), the third summand in the denominator of the RHS in equation (50) then measures the income- (or revenue-)relevant effect of wage taxation on the learning effort. The higher these distortions are, the lower the optimal tax rate should be as well.

Turning to optimal resource investment, this can be derived from multiplying FOC (42) by $E$, rearranging and recognizing that $t^{*}>0$ from (50) as

$$
E^{*}=p^{*} \cdot\left(\frac{V^{H}-V^{L}}{\lambda} \cdot \epsilon_{p E}+t^{*} \cdot\left[w_{H} \cdot H^{*}-w_{L} \cdot L^{*}\right] \cdot\left[\epsilon_{p E}+\epsilon_{p e} \cdot \eta_{e E}\right]\right) .
$$

Thus, there are three effects, determining optimal resource investment: The first summand in the bracket on the RHS of (52) represents the welfare increase, net of financing costs $\lambda$, by an additional household getting into the skilled sector due to an improved quality of the educational sector. Note that, contrary to the First-best solution, the skill premium in (indirect) utility, $V^{H}-V^{L}$, must be positive, in order to have positive effort investment $e>0$ by households.

The second term, $t^{*} \cdot\left[w_{H} \cdot H^{*}-w_{L} \cdot L^{*}\right] \cdot \epsilon_{p E}$, measures increased tax revenue and, accordingly, the self-financing effect, because increasing educational investment will increase the number of skilled tax payers by $\epsilon_{p E}$, paying each additional taxes on the skill premium in wage income.

Finally, the third term, $t^{*} \cdot\left[w_{H} \cdot H^{*}-w_{L} \cdot L^{*}\right] \cdot\left[\epsilon_{p e} \cdot \eta_{e E}\right]$, makes clear that investing in the quality of the educational sector is another way to foster learning

${ }^{20}$ See Appendix 9.2 for a proof of the inequality in equation (51). 
effort $e$ (due to the complementarity in $\eta_{e E}$ ) and to increase educational opportunities. On the one hand, this increases ceteris paribus the number of skilled tax payers again, but on the other hand, and being more important, the increased public spending can mitigate partially distortions in learning effort, caused by implementing a wage tax $t^{*}>0$.

Summarizing our discussion in this subsection so far, we can conclude:

Proposition 2. If skill-specific tuition fees are not available $\left(f_{B}=0\right)$, the government will implement a positive wage tax rate $t^{*}>0$, balancing insurance on the one hand and distortions in labor supply and learning effort on the other hand.

Optimal resource investment in the educational sector $E^{*}$ aims to exploit the skill premia in utility respectively income by increasing educational opportunities and it mitigates tax-induced distortions in learning effort by an increased quality in the educational sector.

In order to describe the full tax policy, we have to determine the optimal lumpsum transfer $T^{*}$. From the governmental budget constraint (33), we have in case of $f_{B}=0$

$$
T^{*}=t^{*} \cdot w_{L}+L^{*}+t^{*} \cdot p^{*} \cdot\left[w_{H} \cdot H^{*}-w_{L} \cdot L^{*}\right]-E^{*} .
$$

Inserting the optimal value of $E^{*}$ from (52), we end up with

$T^{*}=t^{*} w_{L} L^{*}-p^{*} \epsilon_{p E} \frac{V^{H}-V^{L}}{\lambda}-t^{*} p^{*}\left(w_{H} H^{*}-w_{L} L^{*}\right)\left(\epsilon_{p E}+\epsilon_{p e} \eta_{e E}-1\right)$.

From equation (54), we reason

Proposition 3. If either the elasticity of the success probability with respect to educational investment $\epsilon_{p E}$ or its complementary effect via learning effort $\epsilon_{p e} \cdot \eta_{e E}$ or at least the sum of both effects is elastic, $\epsilon_{p E}+\epsilon_{p e} \cdot \eta_{e E}>1$, more than the entire tax revenue from the skill premium is invested in the educational sector and there are no direct transfers from the skilled to the unskilled. Consequently, unskilled workers are net tax payers.

Proof. First, from the conditions on $\epsilon_{p E}+\epsilon_{p e} \eta_{e E}>1$ in Proposition 3 and equa- 
tion (54) it follows that the maximum lump-sum transfer is $T=t^{*} w_{L} L^{*}$, thus all tax payers are maximally entitled to be reimbursed for their payment on unskilled labor income. Hence, the entire revenue from taxing the skill premium $w_{H} H^{*}-w_{L} L^{*}$ must be spent on $E^{*}$. Moreover, there are deductions from this maximum transfer, which have to be invested into the quality of the educational sector as well in order to guarantee a balanced budget of the government. This proves the first statement in Proposition 3.

Due to this spending in the educational sector, there is no money left for cashtransfers from the skilled to the unskilled. In fact, even if the lump sum transfer $T^{*}$ should be positive, unskilled workers are net tax payers, because their overall tax payment $T P_{L}$ is equal to

$$
\begin{aligned}
T P_{L} & =t^{*} \cdot w_{L} \cdot L^{*}-T^{*} \\
& =p^{*} \epsilon_{p E} \frac{V^{H}-V^{L}}{\lambda}+t^{*} p^{*}\left(w_{H} H^{*}-w_{L} L^{*}\right)\left(\epsilon_{p E}+\epsilon_{p e} \eta_{e E}-1\right)>0
\end{aligned}
$$

given the conditions met in Proposition 3. This proves the last statement.

No matter, whether the lump-sum transfer $T^{*}$ remains (somewhat) positive or turns even into a lump-sum tax, Proposition 3 implies that all households have to pay for the educational system, at least as long as the success probability is sufficiently elastic. Unskilled workers are made better of ex ante by increasing their educational opportunities due to investing (strongly) into quality of universities instead of providing income transfers ex post.

Thus, the optimal tax and education policy in case of unavailable skill-specific tuition fees can be summarized as decreasing the variance in wage income by implementing a labor tax and trying to get as many households employed in the skilled sector as possible - given direct resource costs and excess burden caused - for providing ex-ante insurance and for increasing the expected utility of each household.

In the next subsection, we are going to extend the instruments of the government for skill-specific tuition fees and we will show that this fosters the focus on educational opportunities. 


\subsection{The Case of Skill-specific Tuition Fees}

Turning to skill-specific tuition fees, we can solve FOC (39) for $p^{*} \cdot \alpha^{H}$, respectively solve (40) for $-\left(1-p^{*}\right) \cdot \alpha^{L}$. Substituting both rearranged expressions into the first order condition (41) results in

$$
\begin{array}{r}
\left(w_{L} L^{*}-w_{H} H^{*}+f_{B}\right) \cdot \lambda \cdot\left\{p^{*}+p_{e}^{*} \cdot A \cdot \frac{\partial e / \partial f_{B}}{1-t}+p^{*} \cdot t w_{H} \frac{\partial H^{*} / \partial f_{B}}{1-t}\right\} \\
+w_{L} L^{*} \cdot \lambda \cdot\left\{(-1)+p_{e}^{*} \cdot A \cdot \frac{\partial e}{\partial T}+p^{*} \cdot t w_{H} \cdot \frac{\partial H^{*}}{\partial T}+\left(1-p^{*}\right) \cdot t w_{L} \cdot \frac{\partial L^{*}}{\partial T}\right\} \\
+\lambda \cdot\left\{p^{*} \cdot\left(w_{H} H^{*}-f_{B}\right)+\left(1-p^{*}\right) \cdot w_{L} L^{*}\right\} \\
+\lambda \cdot\left\{p_{e}^{*} \cdot A \cdot \frac{\partial e}{\partial t}+p^{*} \cdot t w_{H} \cdot \frac{\partial H^{*}}{\partial t}+\left(1-p^{*}\right) \cdot t w_{L} \cdot \frac{\partial L^{*}}{\partial t}\right\}=0
\end{array}
$$

where $A=\left[t w_{H} H^{*}+(1-t) f_{B}-t w_{L} L^{*}\right]$. After collecting terms and simplifying we apply the Slutsky equations for the derivatives of labor supplies $H^{*}$ and $L^{*}$. Note that the derivatives of decision variables for the lump-sum transfer $T$ are pure income effects, and that $\frac{\partial H^{*} / \partial f_{B}}{1-t}=-\frac{\partial H^{*}}{\partial T}$. Canceling income effects, and rearranging then gives

$$
\begin{aligned}
p_{e}^{*} \cdot A \cdot\left\{\left(w_{L} L^{*}-w_{H} H^{*}+f_{B}\right) \cdot \frac{\partial e / \partial f_{B}}{1-t}+w_{L} L^{*} \cdot \frac{\partial e}{\partial T}+\frac{\partial e}{\partial t}\right\} & \\
-t \cdot\left[p^{*} \cdot w_{H}^{2} \cdot S_{H H}+\left(1-p^{*}\right) w_{L}^{2} \cdot S_{L L}\right] & =0,(57)
\end{aligned}
$$

with $S_{j j}, j=H, L$, as substitution effect of labor supply, when its wage changes.

Applying the comparative-static results from equations (12), (13), and (15), we find that

$$
\left(w_{L} L^{*}-w_{H} H^{*}+f_{B}\right) \cdot \frac{\partial e / \partial f_{B}}{1-t}+w_{L} L^{*} \cdot \frac{\partial e}{\partial T}+\frac{\partial e}{\partial t}=0
$$

If we then define $\epsilon_{H H}=\frac{w_{H}}{H^{*}} \cdot S_{H H}$ as the compensated wage elasticity of skilled labor supply, and $\epsilon_{L L}=\frac{w_{L}}{L^{*}} \cdot S_{L L}$ as the compensated wage elasticity of unskilled labor supply, equation (57) reduces to

$$
t \cdot\left[w_{H} \cdot p^{*} \cdot H^{*} \cdot \epsilon_{H H}+w_{L} \cdot\left(1-p^{*}\right) \cdot L^{*} \cdot \epsilon_{L L}\right]=0 .
$$

Using this result, we derive the following proposition: 
Proposition 4. If the government can use skill-specific tuition fees $f_{B}$ and if the government simultaneously has access to an unconstrained lump-sum transfer $T$, it is not optimal to use a proportional wage tax, hence $t=0$.

Proof. Unconstrained lump-sum transfer implies that this transfer can turn negative, and can be used in order to finance public educational spending. In this case, we can apply the above calculations, and get from (59) directly $t=0$, because the compensated elasticities $\epsilon_{j j}, j=H, L$, and the wage bills of skilled and unskilled worker must be positive, hence the squared bracket in (59) is positive.

Contrary to standard models featuring risky human capital and taxation (e.g. Eaton and Rosen (1980b), Hamilton (1987), but also Anderberg and Andersson (2003)), the distortionary wage tax is not used, although it would provide simultaneously insurance against income risk, and redistribution of resources to households with a higher weight in the social welfare function. Compared to subsection 7.1, the reason is that now skill-specific tuition fees are available, which do not depend on labor supply. These fees are a superior instrument for redistribution, although they distort individual learning effort. The latter distortion can then be countered by public spending in the educational sector.

Making use of $t=0$, we can define the net social marginal value of income (including income effects on the tax base) as

$$
b^{L}=\frac{\alpha^{L}}{\lambda}
$$

for unskilled worker and

$$
b^{H}=\frac{\alpha^{H}}{\lambda}+f_{B} \cdot p_{e} \cdot \frac{\partial e}{\partial T}
$$

for skilled worker. The expected net social marginal value of income then reads

$$
\bar{b}=p^{*} \cdot \frac{\alpha^{H}}{\lambda}+\left(1-p^{*}\right) \cdot \frac{\alpha^{L}}{\lambda}+p^{*} \cdot f_{B} \cdot p_{e} \cdot \frac{\partial e}{\partial T} .
$$

From these definitions and FOC (40) follows, accordingly to the previous sec- 
tion, that the expected net social marginal value of income must be

$$
\bar{b}=1
$$

again.

Applying $t=0$ in the first order condition (39) gives

$$
p^{*} \cdot \frac{\alpha^{H}}{\lambda}-1=f_{B} \cdot p_{e}^{*} \cdot \frac{\partial e}{\partial f_{B}} .
$$

Inserting equation (63) and (62) in the LHS of equation (64), this results after some rearrangements in

$$
f_{B}=-\frac{1-p}{p} \cdot \frac{b^{L}}{\epsilon_{e f_{B}} \cdot \epsilon_{p e}} .
$$

where we defined $\epsilon_{e f_{B}}=\frac{\frac{\partial e}{\partial f_{B}}+p^{*} \cdot \frac{\partial e}{\partial T}}{e}$ as the compensated elasticity of learning effort with respect to skill-specific tuition fees and where $\epsilon_{p e}=\frac{p^{*}(e, E)}{e} \cdot p_{e}^{*}>0$.

If we moreover rely again on $\epsilon_{p e}$ and $\epsilon_{p E}=\frac{p^{*}(e, E)}{E} \cdot p_{E}^{*}>0$ as the elasticities of the success probability and $\eta_{e, E}=\frac{e}{E} \cdot \frac{\partial e}{\partial E}>0$ as the elasticity of learning effort with respect to public educational expenditure, we find from rearranging equation (42)

$$
E=p^{*} \cdot\left[\epsilon_{p E} \cdot \frac{V^{H}-V^{L}}{\lambda}+f_{B} \cdot\left(\epsilon_{p E}+\epsilon_{p e} \cdot \eta_{e E}\right)\right],
$$

and can state

Proposition 5. The optimal financing scheme includes skill-specific tuition fees $f_{B}>0$. Induced distortions in the learning effort are mitigated by a positive public spending in the educational sector, $E>0$.

Proof. As $p \in[0,1)$ and $b^{L}, \epsilon_{p e}>0$ by definition, we have that

$$
\operatorname{sign}\left(f_{B}\right)=-\operatorname{sign}\left(\epsilon_{e f B}\right)
$$


from equation (65). Looking at the results of comparative-statics, we find

$$
\epsilon_{e f B}=\frac{\frac{\partial e}{\partial f_{B}}+p^{*} \cdot \frac{\partial e}{\partial T}}{e}<0,
$$

because $\frac{\partial e}{\partial f_{B}}, \frac{\partial e}{\partial T}<0$ from (13) respectively (12). Hence, $f_{B}>0$.

In case of $f_{B}>0$, it follows at once from equation (66) that the optimal public spending in the education sector must be positive, because all elasticities and the marginal costs of tax revenue $\lambda$ are positive, and an interior solution for learning effort $e$ requires $V^{H}>V^{L} .^{21}$

Now, redistribution is executed by skill-specific tuition fees, which have to be paid by successful workers. The advantage of skill-specific fees is that they do not distort labor supply, and that they are very efficient in redistributing from high income to low income groups. However, they induce a substitution effect in learning effort, because getting graduated gets less attractive.

This gets very clear by looking at equation (65): The net social marginal value of income for an unskilled worker in the numerator of the second fraction on the RHS indicates welfare gains from indirect redistribution (only the skilled are taxed), whereas the denominator balances these welfare gains against distortions in learning effort $\left(\epsilon_{e f_{B}}\right)$, which translate via the elasticity of the probability function $\epsilon_{p e}$ into both a decrease in educational opportunities and in the number of skilled worker. Additionally, this trade-off is weighted be the relative number of unskilled to skilled workers.

The inefficiency caused by skill-specific tuition fees can, however, be partly offset by public funding of the education sector. The more the government spends on education, the higher will be a) the probability of each household to graduate into the skilled sector, and b) - ceteris paribus - private learning effort.

As skill-specific tuition fees reduce the income gap between skilled and unskilled worker, and public spending increases the likelihood of getting graduated, the combination of both instruments also has an insurance effect, because educational and income risk is reduced.

\footnotetext{
${ }^{21}$ Remind that $V^{H} \leq V^{L}$ cannot appear as long as households choose learning effort, because this would imply $e=0$, and $p^{*}(0, E)=0$, which cannot be socially optimal as long as $w_{H}>w_{L}$.
} 
Taken together, efficient redistribution via skill-specific tuition fees, and the insurance function of the combined instruments, discussed above, allows the government to abstain from the wage tax. It is indeed a surprising result that the wage tax is not used in the optimum: Whilst skill-specific tuition fees have a negative substitution effect on learning effort and create therefore an excess burden, wage taxes have distortionary effects on the labor supplies of skilled respectively unskilled households, but - compared to skill-specific tuition fees - provide as well insurance against income risk and have a limited or even offsetting substitution effect on learning effort. ${ }^{22}$ Thus, standard intuition from Second-best models would tell us that one should apply the Lipsey-Lancaster theorem and balance the overall excess burden by using several distorting instruments. However, this is not the case in our setting. Here, increased public expenditure on the education system, $E$, both reduces efficiency costs of tuition fees and provides insurance at lower costs than a wage tax - as long as learning effort is endogenous and there is complementarity between private effort and public endowment of the education system, $p_{e E}>0$.

However, public expenditure in the education sector does not only depend on skill-specific tuition fees:

Corollary 2. Optimal public expenditure for education increases in

(i) the efficiency of the learning technology,

(ii) the complementarity of (private) learning effort and public spending.

Moreover, optimal expenditure E and

(a) skill-specific tuition fees $f_{B}$,

(b) the skill premium, measured in utility, $V^{H}-V^{L}$

are (fiscal or strategic) complements, whereas public expenditure and marginal costs of creating tax revenue are (strategic) substitutes.

Proof. The proof to this Corollary follows directly from equation (66). (a), (b), and the decrease in marginal costs $\lambda$ are straightforward. The efficiency of the

${ }^{22}$ The latter can be seen from equation (15) and its discussion in section 4 . 
learning technology can be measured by the elasticities $\epsilon_{p e}$, and $\epsilon_{p E}$, whereas the complementarity of $e$ and $E$ is an increasing function of $\eta_{e E}$. From (66) it follows that the optimal $E^{*}$ increases in all these elasticities, which proofs parts (i) and (ii).

The intuitions behind these results are as follows: The higher the skill-specific tuition fees are, the higher are the distortions in learning effort. This requires higher public spending for education. In fact, this result is similar to the result in Bovenberg and Jacobs (2005). In order to avoid major inefficiencies, when redistributing from skilled to unskilled, subsidies are necessary. Whilst in Bovenberg and Jacobs (2005) direct subsidies are granted, in our model the government subsidizes education indirectly via improved learning technologies and increased educational opportunities.

The more effective the learning technology is and the more elastic learning effort, the more students can be graduated via educational spending - which can be seen as a kind of redistribution, - and the better each individual can be insured against educational risk via increased opportunities. Last but not least, the greater the difference in utilities of skilled and unskilled worker, the higher the welfare gain, when more workers get into the skilled sector by public spending.

To close the model, we have to determine the optimal lump-sum transfer. For $t=0$, the governmental budget constraint reduces to

$$
E+T=p^{*} \cdot f_{B}
$$

Substituting for $p^{*} \cdot f_{B}$ in equation (66), we end up with

$$
T=\frac{1-\left(\epsilon_{p E}+\epsilon_{p e} \cdot \eta_{e E}\right)}{\epsilon_{p E}+\epsilon_{p e} \cdot \eta_{e E}} \cdot E-p^{*} \cdot \epsilon_{p E} \cdot \frac{V^{H}-V^{L}}{\lambda}
$$

Obviously, the optimal lump-sum transfer turns out to be a real lump-sum $\operatorname{tax} T<0$, unless the success probability is very inelastic, and hence unless the learning technology is very inefficient.

Proposition 6. Some part of public expenditure is financed by a general lump sum tax, $T<0$, if the success probability with respect to public spending $\epsilon_{p E}$ or 
its complementary effect via learning effort $\epsilon_{p e} \cdot \eta_{e E}$ or at least the sum of both effects is elastic, $\epsilon_{p E}+\epsilon_{p e} \cdot \eta_{e E}>1$.

Proof. Proposition 6 follows directly from (70), and recognizing that $V^{H}>V^{L}$.

Analogously to Proposition 3 in the previous section, the educational system will be financed by both the skilled and the unskilled worker, if the learning technology is not too inefficient. Skill-specific tuition fees are therefore not used to redistribute income directly to the unskilled, but are used in order to provide better chances in the educational system. Thus, even if more information is available to the government and it can apply skill-specific tuition fees, educational opportunities play a major role.

Moreover, the lump-sum tax is increasing - at least in some range - in the effectivity of public spending $\epsilon_{p E}$, because the second term in (70) tends to infinity, if $\epsilon_{p E} \rightarrow \infty$, whereas the first term tends to zero, if $\epsilon_{p E} \rightarrow \infty$, and the sum tends to infinity.

Of course, lump-sum taxation is not very realistic and not very appealing in a Second-best world. In our model, the lump-sum tax can, fortunately, have another interpretation as well: $-T$ can be seen as general tuition fee, which has to be paid irrespectively whether a student is successful in educational investment. Overall tuition fees are then $F=-T+f_{B}$, whereby these will only be paid in full by the skilled. Hence, our model and our results argue in favor of general tuition fees, which are only partially pre-financed and insured by skill-specific tuition fees.

\subsection{Comparison to First-best: Educational Opportunities Matter}

Finally, we want to address the question of direct income insurance versus insurance via educational opportunities. We have seen in the First-best analysis that direct income insurance is always guaranteed by equalized (ex-post) marginal utilities of income and that resource investment in the educational sector only depends on the skill premium in utility and on resource gains for redistribution by increasing the number of skilled households. All this changes distinctly, if the 
government has limited instruments available, as it cannot control private learning effort directly.

In a Second-best setting, any direct income redistribution has negative incentive effects on learning effort and causes moral hazard, as the government cannot control, if and how time is spent at university. In case of endogenous success probabilities and educational opportunities, (wage) taxation gets therefore even more expensive, because not only labor supply may be distorted. Taken together, these effects weaken the case for income insurance, which provides the core intuition in risk-and-insurance papers à la Eaton and Rosen (1980a,b).

At the same time, induced distortions in learning ceteris paribus call for increased public spending on education, in order to dampen the moral hazard effect. Moreover, comparing the First-best level of learning effort in equation (23) with the household's first order condition (8), we see that the households neglect the resource increasing effect on behalf of the government, the last term in equation (23). Accordingly, there is another reason for underinvestment in effort, which has to be countered by increased public spending. This need for public spending would persist even in a setting with private investment into the quality of universities.

Comparing the First-best efficient level of real investment $E$ in equation (32) and the Second-best level, determined in equation (66), these two effects are represented by the second term in the squared bracket on the RHS of (66), $p^{*} \cdot f_{B} \cdot \epsilon_{p e} \cdot \eta_{e E}$.

Next, the skill premium, measured in utility $V^{H}-V^{L}$, turns positive in a Second-best optimum. This ceteris paribus increases educational investment, because an additional graduate increases social welfare, now. However, the marginal costs of providing $E$ also increase, because now $\lambda$ not only reflects marginal utility of income, but also induced distortions costs, which ceteris paribus have a negative effect on $E$. Although the government most likely increases its real investment, nothing can be said on the success probability $p^{*}$, because private learning effort is likely to decline.

Last, but not least, introducing a general tuition fee (a negative lump-sum transfer $T<0$ ) decreases income and induces higher learning effort according to equation (12). The lump-sum tax can therefore be justified by aiming to increase 
educational opportunities as well.

Collecting all the effects described above, we can state:

Proposition 7. In a Second-best world, increasing educational opportunities matters (compared to the First-best solution) more than providing income insurance, because providing directly (full) insurance via income transfers $(T>0)$ gets (too) expensive, and because public resource investment also corrects for inefficiencies in private learning effort in a relatively cheap manner.

This result is robust, even if the government suffers from stricter informational restrictions and cannot implement skill-specific tuition fees via $f_{B}$. The call for improving educational opportunities and the preferability over income transfers is at the heart of Proposition 3 in subsection 7.1 as well.

The absence of wage taxation and part of the shift from income insurance to increased educational opportunities are, however, sensitive to our focus on educational risk and the absence of wage risks within one skill group. Introducing additionally income risks, e.g., in the skilled sector, might lead, in a Second-best setting, to positive graduate taxation of the Eaton/Rosen-type, which then distorts labor supply of the skilled. If so, this might give rise for general wage taxation as well, and for distorted labor supply decisions in the skilled and the unskilled sector according to the Lipsey-Lancaster-theorem. Nevertheless, educational opportunities and public investment into the quality of the educational sector still play a prominent role in such a setting, and we think that it is worth wile to examine these extensions in more detail in future research.

\section{Conclusions}

We examine the effects of endogenous human capital risk, where the probability of getting an employment in the skilled sector is endogenously determined by individuals, and depends therefore also on tax instruments. We apply a model, where households first choose their learning effort and after realization of risk, they choose their labor supply. We show that a distorting wage tax will not be used, although it would be optimal, if skill-specific tuition fees are not available. Thus, the standard trade-off between distortions in labor supply and insurance 
against income risk does not apply. Skill-specific tuition fees can achieve redistribution between skilled and unskilled households, and grant some insurance. The distortions in learning effort, induced by skill-specific fees, are mitigated by public spending in the educational sector. In addition, this public education funding is another instrument for redistribution.

Taken together, we are able to state that increasing educational opportunities, measured as success probability in graduation, is preferable to providing income transfers, as the latter get (too) expensive in a Second-best world. Thus, redistribution in an ex-ante sense is more important than spending resources for 'healing' bad outcomes ex post. This holds even if skill-specific tuition fees via $f_{B}$ are not available.

\section{Appendix}

\subsection{Derivation of Equation (50)}

From inserting $f_{B}=0$ and rearranging FOC (41), we obtain

$$
\begin{aligned}
& \frac{p^{*} \alpha^{H} w_{H} H^{*}+\left(1-p^{*}\right) \alpha^{L} w_{L} L^{*}}{\lambda}-p^{*} w_{H} H^{*}+\left(1-p^{*}\right) w_{L} L^{*} \\
= & p^{*} t w_{H} \frac{\partial H}{\partial t}+\left(1-p^{*}\right) t w_{L} \frac{\partial L}{\partial t}+t\left(w_{H} H^{*}-w_{L} L^{*}\right) p_{e} \frac{\partial e}{\partial t} .
\end{aligned}
$$

Steiner's rule implies

$$
\begin{aligned}
\operatorname{Cov}\left(b^{j}, w_{j} Z^{j}\right)= & \mathrm{E}\left[b^{j} \cdot w_{j} Z_{j}\right]-\mathrm{E}\left[b^{j}\right] \cdot \mathrm{E}\left[w_{j} Z_{j}\right] \\
= & \frac{p^{*} \alpha^{H} w_{H} H^{*}+\left(1-p^{*}\right) \alpha^{L} w_{L} L^{*}}{\lambda} \\
& +p^{*} t w_{H} \frac{\partial H}{\partial T} w_{H} H^{*}+\left(1-p^{*}\right) t w_{L} \frac{\partial L}{\partial T} w_{L} L^{*} \\
& +t\left(w_{H} H^{*}-w_{L} L^{*}\right) p_{e} \frac{\partial e}{\partial T}\left[p^{*} w_{H} H^{*}+\left(1-p^{*}\right) w_{L} L^{*}\right] \\
& -p^{*} w_{H} H^{*}+\left(1-p^{*}\right) w_{L} L^{*}
\end{aligned}
$$

because $\mathrm{E}\left[b^{j}\right]=1$ from equation (45).

Adding $\quad p^{*} \quad t \quad w_{H} \quad \frac{\partial H}{\partial T} \quad w_{H} H^{*}+\left(1-p^{*}\right) \quad t \quad w_{L} \quad \frac{\partial L}{\partial T} \quad w_{L} L^{*}+$ 
$t\left(w_{H} H^{*}-w_{L} L^{*}\right) p_{e} \frac{\partial e}{\partial T}\left[p^{*} w_{H} H^{*}+\left(1-p^{*}\right) w_{L} L^{*}\right]$ on both sides of (71), we can make use of Steiner's rule (72) on the LHS of (71) in order to receive

$$
\begin{aligned}
\operatorname{Cov}\left(b^{j}, w_{j} Z_{j}\right) & =p^{*} t w_{H}\left[\frac{\partial H}{\partial t}+\frac{\partial H}{\partial T} \cdot w_{H} H^{*}\right] \\
& +\left(1-p^{*}\right) t w_{L}\left[\frac{\partial L}{\partial t}+\frac{\partial L}{\partial T} \cdot w_{L} L^{*}\right] \\
& +t\left(w_{H} H^{*}-w_{L} L^{*}\right) p_{e}\left[\frac{\partial e}{\partial t}+\frac{\partial e}{\partial T} \cdot \mathrm{E}\left[w_{j} Z_{j}\right]\right]
\end{aligned}
$$

where $\mathrm{E}\left[w_{j} Z_{j}\right]=\left[p^{*} w_{H} H^{*}+\left(1-p^{*}\right) w_{L} L^{*}\right]$.

Relying on the Slutsky decompositions, these imply

$$
\begin{aligned}
\frac{\partial H}{\partial t} & =\left[S_{H H}+H^{*} \cdot \frac{\partial H}{\partial T}\right] \cdot\left(-w_{H}\right), \\
\frac{\partial L}{\partial t} & =\left[S_{L L}+L^{*} \cdot \frac{\partial L}{\partial T}\right] \cdot\left(-w_{L}\right), \\
\frac{\partial e}{\partial t} & =\left[S_{e \bar{w}}+\bar{Z} \cdot \frac{\partial e}{\partial T}\right] \cdot(-\bar{w}),
\end{aligned}
$$

whereby $S_{j j}>0$ represents the substitution effect with regard to the own wage and $S_{e \bar{w}}$ is the substitution effect of a change in the expected wage $\bar{w}$ on learning effort. Moreover, $\bar{Z}=\mathrm{E}\left[Z_{j}\right]=p^{*} H^{*}+\left(1-p^{*}\right) L^{*}$ and $\bar{w}=\mathrm{E}\left[w_{j}\right]=p^{*} w_{H}+$ $\left(1-p^{*}\right) w_{L}$.

When we revert to equations (74) to (76) and cancel income effects in equation (73), where possible, we are left with

$$
\begin{aligned}
\operatorname{Cov}\left(b^{j}, w_{j} Z_{j}\right) & =p^{*} t w_{H} S_{H H}\left(-w_{H}\right)+\left(1-p^{*}\right) t w_{L} S_{L L}\left(-w_{L}\right) \\
& +t\left(w_{H} H^{*}-w_{L} L^{*}\right) p_{e} \cdot\left[S_{e \bar{w}}(-\bar{w})+\left(\mathrm{E}\left[w_{j} Z_{j}\right]-\bar{w} \bar{Z}\right) \cdot \frac{\partial e}{\partial T}\right]
\end{aligned}
$$

Making use of Steiner's rule again, the parenthesis in the last line of equation (77) turns into

$$
\mathrm{E}\left[w_{j} Z_{j}\right]-\bar{w} \bar{Z}=\operatorname{Cov}\left(w_{j}, Z_{j}\right),
$$

and dividing equation (77) on both sides by expected wage income $\mathrm{E}\left[w_{j} Z_{j}\right]=$ $p^{*} w_{H} H^{*}+\left(1-p^{*}\right) w_{L} L^{*}$, multiplying by minus one, and applying the definitions 
in equations (46) to (49) as well as

$$
\psi=\frac{\operatorname{Cov}\left(w_{j}, Z_{j}\right)}{\bar{w} \cdot\left[p^{*} \cdot H+\left(1-p^{*}\right) \cdot L\right]}>0 \quad \text { and } \quad \eta_{e T}=\frac{(1-t) \cdot \bar{w} \cdot \bar{Z}}{e} \cdot \frac{\partial e}{\partial T}<0,
$$

results in

$$
\chi=\frac{t}{1-t} \cdot\left\{\bar{\epsilon}_{H H}+\bar{\epsilon}_{L L}+\frac{p^{*}\left(w_{H} H^{*}-w_{L} L^{*}\right)}{p^{*} w_{H} H^{*}+\left(1-p^{*}\right) w_{L} L^{*}} \epsilon_{p e} \cdot\left[\epsilon_{e \bar{w}}-\psi \eta_{e T}\right]\right\} .
$$

As the squared bracket on the RHS is positive from equation (51) and all other terms are positive by definition, the optimal tax rate $t^{*}$ must be positive as well. This then proves equation (50).

\subsection{Derivation of Equation (51)}

Inferred from the steps in Appendix 9.1 and equations (78) and (73), it is

$$
\epsilon_{e \bar{w}}-\psi \eta_{e T}=-\left[\frac{\partial e}{\partial t}+\frac{\partial e}{\partial T} \cdot \mathrm{E}\left[w_{j} Z_{j}\right]\right]
$$

By inserting some comparative statics results, (15) and (12), this turns into

$$
\begin{aligned}
\epsilon_{e \bar{w}}-\psi \eta_{e T} & =\frac{p_{e} \cdot\left\{\alpha^{L} w_{L} L^{*}-\alpha^{H} w_{H} H^{*}+\left(\alpha^{H}-\alpha^{L}\right) \mathrm{E}\left[w_{j} Z_{j}\right]\right\}}{S O C(e)} \\
& =-\frac{p_{e} \cdot\left\{\left[\left(1-p^{*}\right) \alpha^{H}+p \alpha^{L}\right]\left(w_{H} H^{*}-w_{L} L^{*}\right)\right\}}{S O C(e)} \\
& >0
\end{aligned}
$$

whereby $\mathrm{E}\left[w_{j} Z_{j}\right]=p w_{H} H^{*}+\left(1-p^{*}\right) w_{L} L^{*}$.

The inequality in (82) stems thereby from the fact that $S O C(e)<0$ from (11), $w_{H} H^{*}>w_{L} L^{*}$ due to assuming agent monotonicity, $p \in[0,1)$ and $p_{e}, \alpha^{H}, \alpha^{L}>0$. This proves equation (51). 


\section{References}

Anderberg, D. And F. Andersson (2003): "Investments in Human Capital, Wage Uncertainty, and Public Policy," Journal of Public Economics, 87, 15211537.

Andersson, F. AND K. Konrad (2003a): "Globalization and Risky HumanCapital Investment," International Tax and Public Finance, 10, 211-228.

- (2003b): "Human Capital Investment and Globalization in Extortionary States," Journal of Public Economics, 87, 1539-1555.

Boadway, R. W., M. Marchand, and P. Pestieau (1991): “Optimal Linear Income Taxation in Models with Occupational Choice," Journal of Public Economics, 46, 133-162.

Bovenberg, A. L. And B. Jacobs (2005): "Redistribution and Education Subsidies are Siamese Twins," Journal of Public Economics, 89, 2005-2035.

Carneiro, P., K. T. Hansen, And J. J. Heckman (2003): "Estimating Distributions of Treatment Effects with an Application to the Returns to Schooling and Measurement of the Effects of Uncertainty on College Choice," International Economic Review, 44, 361-422.

EATON, J. AND H. S. Rosen (1980a): "Labor Supply, Uncertainty, and Efficient Taxation," Journal of Public Economics, 14, 365-374.

- (1980b): "Taxation, Human Capital, and Uncertainty," American Economic Review, 70, 705-715.

EU-COMMISSION (2007): "Slow pace of reform in education and training threatens Europe's competitiveness in the long term," EU Press Release, IP-07-1431.

EU-CounciL (2005): "Meeting of the European Council. Conclusions of the President," EU DOC-05-1.

García-PeÑAlosA, C. AND K. WÄLdE (2000): "Efficiency and Equity Effects of Subsidies to Higher Education," Oxford Economic Papers, 52, 702-722. 
Glomm, G. AND B. Ravikumar (1992): "Public versus Private Investment in Human Capital Endogenous Growth and Income Inequality,' Journal of Political Economy, 100, 813-834.

Hamilton, J. H. (1987): "Optimal Wage and Income Taxation with Wage Uncertainty," International Economic Review, 28, 373-388.

JACOBS, B. (2002): "An Investigation of Education Finance Reform. Income Contingent Loans and Graduate Taxes in the Netherlands," CPB Discussion Paper No. 9, CPB Netherlands Bureau for Economic Policy Research, Den Haag.

_ (2004): “The Lost Race between Schooling and Technology," DeEconomist, 152, 47-78.

JACOBS, B. AND L. A. Bovenberg (2008): “Optimal Taxation of Human Capital and the Earnings Function," Mimeo.

JACOBS, B. AND S. J. VAN WiJnBERGEN (2007): “Capital-Market Failure, Adverse Selection, and Equity Financing of Higher Education," FinanzArchiv, 63, forthcoming.

Kanbur, S. M. R. (1980): “Risk taking and Taxation,” Journal of Public Economics, $15,163-184$.

KATZ, L. F. And D. H. Autor (1999): Changes in the Wage Structure and Earnings Inequality, Amsterdam: Elsevier Science, vol. 3, chap. 26, 14631555.

KodDE, D. A. (1986): "Uncertainty and the Demand for Education," Review of Economics and Statistics, 68, 460-467.

(1988): "Unemployment Expectations and Human Capital Formation," European Economic Review, 32, 1645-1660.

Krugman, P. (1995): "Growing World Trade: Causes and Consequences," Brookings Papers on Economic Activity, 1, 327-377. 
LEVHARI, D. AND Y. WeISS (1974): "The Effect of Risk on the Investment in Human Capital," American Economic Review, 64, 950-963.

Maldonado, D. (2008): "Education Policies and Optimal Taxation," International Tax and Public Finance, 15, 131-143.

Mirrlees, J. A. (1976): “Optimal Tax Theory: A Synthesis,” Journal of Public Economics, 6, 327-358.

OECD (2007): Education at a Glance 2007, Paris: OECD.

SINN, H.-W. (1996): "Social Insurance, Incentives, and Risk-taking," International Tax and Public Finance, 3, 259-280.

Wigger, B. U. AND R. VON WeIZSÄCKER (2001): "Risk, Resources, and Education - Public versus Private Financing of Higher Education," IMF Staff Papers, 48, 547-560.

WILDASIN, D. E. (2000): "Labor-Market Integration, Investment in Risky Human Capital, and Fiscal Competition.” American Economic Review, 90, 73-95. 


\section{CESifo Working Paper Series}

for full list see www.cesifo-group.org/wp

(address: Poschingerstr. 5, 81679 Munich, Germany, office@cesifo.de)

2285 Axel Dreher and Stefan Voigt, Does Membership in International Organizations Increase Governments' Credibility? Testing the Effects of Delegating Powers, April 2008

2286 Xavier Freixas and Bruno M. Parigi, Lender of Last Resort and Bank Closure Policy, April 2008

2287 Regina Dionisius, Samuel Muehlemann, Harald Pfeifer, Günter Walden, Felix Wenzelmann and Stefan C. Wolter, Cost and Benefit of Apprenticeship Training - A Comparison of Germany and Switzerland, April 2008

2288 Francesco Daveri and Cecilia Jona-Lasinio, Off-Shoring and Productivity Growth in the Italian Manufacturing Industries, April 2008

2289 Mikael Priks, Do Surveillance Cameras Affect Unruly Behavior? A Close Look at Grandstands, April 2008

2290 Marianna Belloc and Daniela Federici, A Two-Country NATREX Model for the Euro/Dollar, April 2008

2291 Nicolas Treich, The Value of a Statistical Life under Ambiguity Aversion, April 2008

2292 J. Atsu Amegashie, Socially-Tolerable Discrimination, April 2008

2293 M. Hashem Pesaran and Andreas Pick, Forecasting Random Walks Under Drift Instability, April 2008

2294 Steven Brakman, Gus Garita, Harry Garretsen and Charles van Marrewijk, Unlocking the Value of Cross-Border Mergers and Acquisitions, May 2008

2295 Eric O’N. Fisher and Kathryn G. Marshall, The Structure of the American Economy, May 2008

2296 Claudia M. Buch and Martin Schlotter, Regional Origins of Employment Volatility: Evidence from German States, May 2008

2297 Helmuth Cremer, Philippe De Donder, Dario Maldonado and Pierre Pestieau, Taxing Sin Goods and Subsidizing Health Care, May 2008

2298 Reinhilde Veugelers and Frederick van der Ploeg, Reforming European Universities: Scope for an Evidence-Based Process, May 2008

2299 Jon H. Fiva and Lars J. Kirkebøen, Does the Housing Market React to New Information on School Quality?, May 2008 
2300 Tina Klautke and Alfons J. Weichenrieder, Interest Income Tax Evasion, the EU Savings Directive, and Capital Market Effects, May 2008

2301 Harald Badinger and Peter Egger, GM Estimation of Higher Order Spatial Autoregressive Processes in Panel Data Error Component Models, May 2008

2302 Jan K. Brueckner, Slot-Based Approaches to Airport Congestion Management, May 2008

2303 Sören Blomquist, Vidar Christiansen and Luca Micheletto, Public Provision of Private Goods and Nondistortionary Marginal Tax Rates, May 2008

2304 Dan Anderberg and Alessandro Balestrino, The Political Economy of Post-Compulsory Education Policy with Endogenous Credit Constraints, May 2008

2305 Tomer Blumkin, Yoram Margalioth and Efraim Sadka, The Role of Stigma in the Design of Welfare Programs, May 2008

2306 Vesa Kanniainen and Paolo M. Panteghini, Tax Neutrality: Illusion or Reality? The Case of Entrepreneurship, May 2008

2307 Thomas Dohmen, Armin Falk, David Huffman and Uwe Sunde, The Intergenerational Transmission of Risk and Trust Attitudes, May 2008

2308 Guglielmo Maria Caporale and Mario Cerrato, Using Chebyshev Polynomials to Approximate Partial Differential Equations, May 2008

2309 Peter Egger and Doina Maria Radulescu, Labour Taxation and Foreign Direct Investment, May 2008

2310 Laurent Linnemer, Dissipative Advertising Signals Quality even without Repeat Purchases, May 2008

2311 Jordi Jofre-Monseny and Albert Solé-Ollé, Which Communities should be afraid of Mobility? The Effects of Agglomeration Economies on the Sensitivity of Firm Location to Local Taxes, May 2008

2312 Andreas Haufler and Ferdinand Mittermaier, Unionisation Triggers Tax Incentives to Attract Foreign Direct Investment, May 2008

2313 Ronel Elul and Piero Gottardi, Bankruptcy: Is it enough to Forgive or must we also Forget?, May 2008

2314 Andreas Irmen and Johanna Kuehnel, Productive Government Expenditure and Economic Growth, May 2008

2315 Beate Henschel, Carsten Pohl and Marcel Thum, Demographic Change and Regional Labour Markets: The Case of Eastern Germany, May 2008 
2316 Gabriel Felbermayr, Wido Geis and Wilhelm Kohler, Restrictive Immigration Policy in Germany: Pains and Gains Foregone?, May 2008

2317 Michael Hofmann, Gerhard Kempkes and Helmut Seitz, Demographic Change and Public Sector Budgets in a Federal System, May 2008

2318 Paul De Grauwe, Macroeconomic Modeling when Agents are Imperfectly Informed, June 2008

2319 Johann K. Brunner and Susanne Pech, Optimum Taxation of Inheritances, June 2008

2320 Thomas Eichner and Marco Runkel, Corporate Income Taxation of Multinationals in a General Equilibrium Model, June 2008

2321 Rainald Borck and Matthias Wrede, Subsidies for Intracity and Intercity Commuting, June 2008

2322 Patricia Apps and Ray Rees, Testing the Pareto Efficiency of Household Resource Allocations, June 2008

2323 Amihai Glazer, Vesa Kanniainen and Panu Poutvaara, Firms' Ethics, Consumer Boycotts, and Signalling, June 2008

2324 Claudia M. Buch, Jörg Döpke and Kerstin Stahn, Great Moderation at the Firm Level? Unconditional vs. Conditional Output Volatility, June 2008

2325 Helmuth Cremer, Philippe De Donder, Dario Maldonado and Pierre Pestieau, Forced Saving, Redistribution and Nonlinear Social Security Schemes, June 2008

2326 M. Hashem Pesaran and Paolo Zaffaroni, Optimal Asset Allocation with Factor Models for Large Portfolios, June 2008

2327 Harald Badinger and Peter Egger, Horizontal versus Vertical Interdependence in Multinational Activity, June 2008

2328 Jan K. Brueckner and Harris Selod, A Theory of Urban Squatting and Land-Tenure Formalization in Developing Countries, June 2008

2329 Paolo M. Panteghini, Corporate Debt, Hybrid Securities and the Effective Tax Rate, June 2008

2330 Guglielmo Maria Caporale, Juncal Cuñado and Luis A. Gil-Alana, Modelling Long-Run Trends and Cycles in Financial Time Series Data, June 2008

2331 Avi Ben-Bassat and Momi Dahan, Social Identity and Voter Turnout, June 2008

2332 Martin R. West and Ludger Wößmann, "Every Catholic Child in a Catholic School”: Historical Resistance to State Schooling, Contemporary Private Competition, and Student Achievement across Countries, June 2008 
2333 Erkki Koskela and Panu Poutvaara, Outsourcing and Labor Taxation in Dual Labor Markets, June 2008

2334 Philippe Choné and Laurent Linnemer, Optimal Litigation Strategies with Signaling and Screening, June 2008

2335 Albert Solé-Ollé and Pilar Sorribas-Navarro, Does Partisan Alignment Affect the Electoral Reward of Intergovernmental Transfers?, June 2008

2336 Antonio Cabrales and Piero Gottardi, Markets for Information: Of Inefficient Firewalls and Efficient Monopolies, June 2008

2337 Sumon Majumdar and Sharun W. Mukand, The Leader as Catalyst - on Leadership and the Mechanics of Institutional Change, June 2008

2338 Ulrich Hange, Tax Competition, Elastic Labor Supply, and Growth, June 2008

2339 Guy Laroque and Bernard Salanié, Does Fertility Respond to Financial Incentives?, June 2008

2340 Adriano Paggiaro, Enrico Rettore and Ugo Trivellato, The Effect of Extending the Duration of Eligibility in an Italian Labour Market Programme for Dismissed Workers, June 2008

2341 Helmut Seitz, Minimum Standards, Fixed Costs and Taxing Autonomy of Subnational Governments, June 2008

2342 Robert S. Chirinko, Leo de Haan and Elmer Sterken, Asset Price Shocks, Real Expenditures, and Financial Structure: A Multi-Country Analysis, July 2008

2343 Wolfgang Leininger, Evolutionarily Stable Preferences in Contests, July 2008

2344 Hartmut Egger and Udo Kreickemeier, Fairness, Trade, and Inequality, July 2008

2345 Ngo Van Long and Bodhisattva Sengupta, Yardstick Competition, Corruption, and Electoral Incentives, July 2008

2346 Florian Baumann, Employment Protection: The Case of Limited Enforceability, July 2008

2347 Alessandro Balestrino, Cinzia Ciardi and Claudio Mammini, On the Causes and Consequences of Divorce, July 2008

2348 Dirk Schindler and Benjamin Weigert, Insuring Educational Risk: Opportunities versus Income, July 2008 